\title{
Computational Flow Modeling of a Simplified Integrated Tractor-Trailer Geomety
}

K. Salari, M. McWherter-Payne

September 19, 2003 


\section{DISCLAIMER}

This document was prepared as an account of work sponsored by an agency of the United States Government. Neither the United States Government nor the University of California nor any of their employees, makes any warranty, express or implied, or assumes any legal liability or responsibility for the accuracy, completeness, or usefulness of any information, apparatus, product, or process disclosed, or represents that its use would not infringe privately owned rights. Reference herein to any specific commercial product, process, or service by trade name, trademark, manufacturer, or otherwise, does not necessarily constitute or imply its endorsement, recommendation, or favoring by the United States Government or the University of California. The views and opinions of authors expressed herein do not necessarily state or reflect those of the United States Government or the University of California, and shall not be used for advertising or product endorsement purposes.

This is a preprint of a paper intended for publication in a journal or proceedings. Since changes may be made before publication, this preprint is made available with the understanding that it will not be cited or reproduced without the permission of the author.

This work was performed under the auspices of the United States Department of Energy by the University of California, Lawrence Livermore National Laboratory under contract No. W-7405-Eng-48. 
SAND2001-\#\#\#\#

Unlimited Release

Printed September 2003

\title{
Computational Flow Modeling of a Simplified Integrated Tractor-Trailer Geometry
}

\author{
Kambiz Salari \\ Computational Physics Group \\ Lawrence Livermore National Laboratory \\ P.O. Box 808, L-228, Livermore, California 94551 \\ Mary McWherter-Payne \\ Aerosciences and Compressible Fluid Mechanics Department \\ Sandia National Laboratories \\ P.O. Box 5800 \\ Albuquerque, New Mexico 87185-0825
}

\begin{abstract}
For several years, Sandia National Laboratories and Lawrence Livermore National Laboratory have been part of a consortium funded by the Department of Energy to improve fuel efficiency of heavy vehicles such as Class 8 trucks through aerodynamic drag reduction. The objective of this work is to demonstrate the feasibility of using the steady Reynolds-Averaged Navier-Stokes (RANS) approach to predict the flow field around heavy vehicles, with special emphasis on the base region of the trailer, and to compute the aerodynamic forces. In particular, Sandia's computational fluid dynamics code, SACCARA, was used to simulate the flow on a simplified model of a tractor-trailer vehicle. The results are presented and compared with NASA Ames experimental data to assess the predictive capability of RANS to model the flow field and predict the aerodynamic forces.
\end{abstract}


Intentionally Left Blank 


\section{Table of Contents}

Abstract

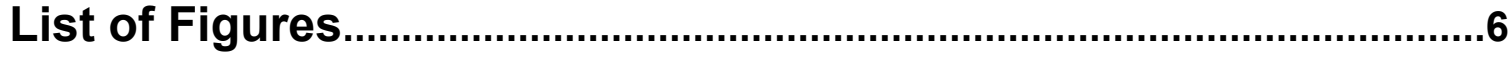

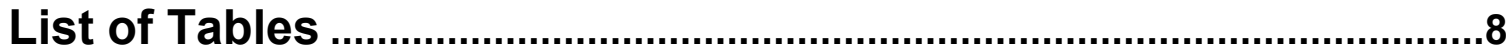

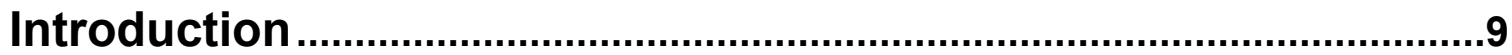

Computational Methodology and Simulations ...........................................11

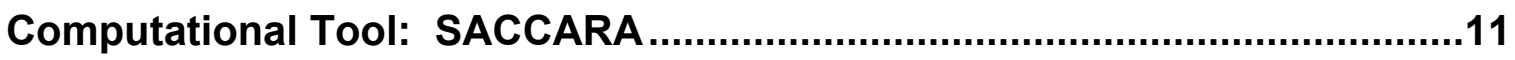

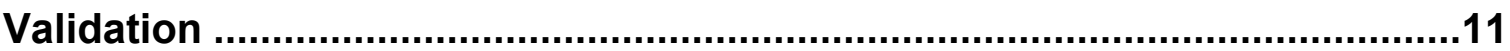

Discussion of Experimental Conditions and SACCARA Results.................12

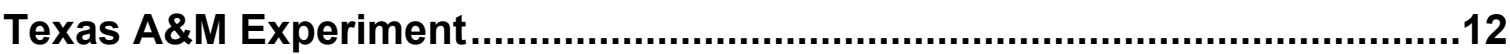

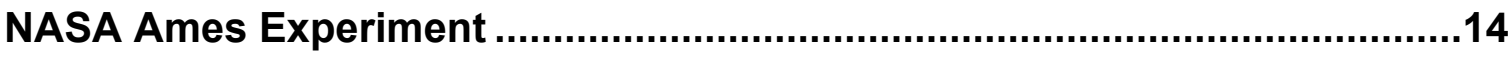

Conclusions and Recommendations for Future Work...............................22

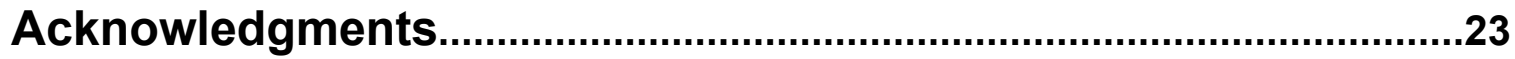

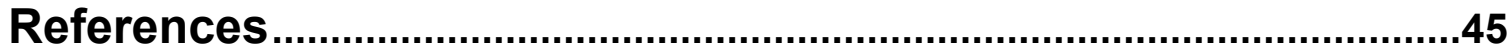




\section{List of Figures}

Figure 1: GTS model in Texas A\&M 7'x10' wind tunnel. ......................................... 24

Figure 2: Coarse mesh of GTS model in Texas A\&M 7'x10' wind tunnel.......................... 24

Figure 3: GTS flow simulation, 2-D, Mach contours................................................... 25

Figure 4: GTS flow simulation, 2-D, pressure contours .............................................. 25

Figure 5: Mach contour, yz slice, $0^{\circ}$ yaw (left), $10^{\circ}$ yaw (right). ...................................... 26

Figure 6: Mach contour, $x z$ slice, $0^{\circ}$ yaw (left), $10^{\circ}$ yaw (right). ....................................... 26

Figure 7: Mach contour, xy slice, $0^{\circ}$ yaw (left), $10^{\circ}$ yaw (right)........................................ 26

Figure 8: Mach contour, yz slice, $x=2.5 \mathrm{~m}$ (left), $x=3.25 \mathrm{~m}$ (right), $10^{\circ}$ yaw, coarse

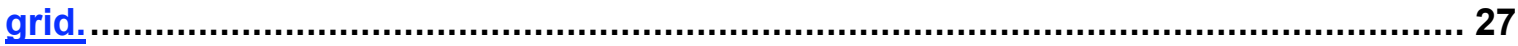

Figure 9: Mach contour, $y z$ slice, $x=2.5 \mathrm{~m}$ (left), $x=3.25 \mathrm{~m}$ (right), $10^{\circ}$ yaw, medium

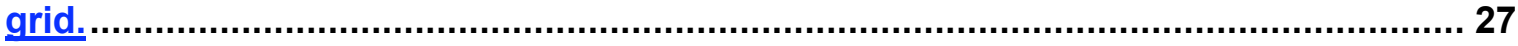

Figure 10: Mach contour, $x z$ slice, $y=0.122 \mathrm{~m}$ (left), $y=-0.035 \mathrm{~m}$ (right), $10^{\circ}$ yaw,

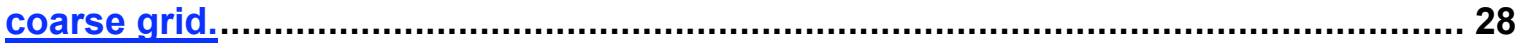

Figure 11: Mach contour, $x z$ slice, $y=0.122 \mathrm{~m}$ (left), $y=-0.035 \mathrm{~m}$ (right), $10^{\circ}$ yaw, medium grid..................................................................................................... 28

Figure 12: Mach contour, xy slice, $z=0.07 \mathrm{~m}$ (left), $z=0.215 \mathrm{~m}$ (right), $10^{\circ}$ yaw, medium grid.

Figure 13: Mach contour, xy slice, $z=0.07 \mathrm{~m}$ (left), $z=0.215 \mathrm{~m}$ (right), $10^{\circ}$ yaw,

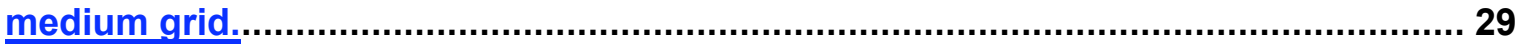

Figure 14: Particle traces colored by Mach number, $0^{\circ}$ yaw, medium grid....................... 30

Figure 15: Particle traces colored by Mach number, $10^{\circ}$ yaw, and medium grid.............. 31

Figure 16: Iso-Surface for $u=-0.001$, coarse grid (left), medium grid (right), $10^{\circ}$ yaw. ...... 32

Figure 17: NASA Ames Experiment: GTS model installation top view (dimensions in inches).

Figure 18: GTS geometry and pressure tap locations. All measurements non-

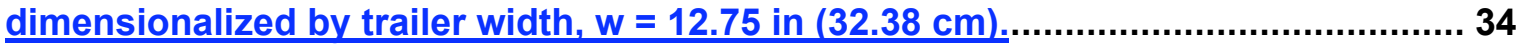

Figure 19: GTS model installation side view (dimensions in inches).............................. 35

Figure 20: Schematic of a portion of the NASA $7 \times 10$ wind tunnel.................................... 35

Figure 21: Boundary layer profile, NASA 7x10 test section centerline. ............................ 36

Figure 22: NASA 7x10 wind tunnel, pressure contours.................................................... 36

Figure 23: NASA $7 \times 10$ wind tunnel, center plane, Mach contours. .................................. 37

Figure 24: NASA $7 \times 10$ wind tunnel, Iso-Surface plot, u-component of velocity,

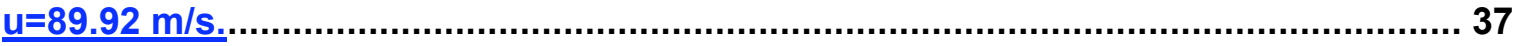

Figure 25: NASA $7 \times 10$ wind tunnel, Iso-Surface plot, v-component of velocity,

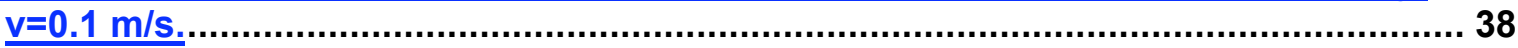

Figure 26: NASA 7×10 wind tunnel, Iso-Surface plot, w-component of velocity, w=-

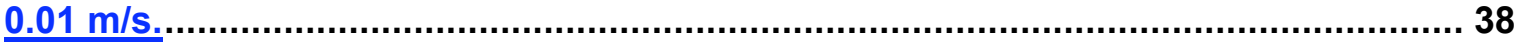

Figure 27: NASA 7x10 wind tunnel, Iso-Surface plot, pressure, $\mathrm{p}=97613 \mathrm{~Pa} . . . . . . . . . . . . . . . .39$

Figure 28: GTS model in NASA Ames 7x10 tunnel ..................................................... 39

Figure 29: Medium mesh of the GTS model in NASA $7 \times 10$ tunnel ................................. 40 
Figure 30: Mach Contours on Cutting Planes for Spalart-Allmaras Solution (Medium Mesh) .................................................................................................. 40

Figures 31: Centerline Front, Top of Truck Pressure Coefficient.................................. 41

Figures 32: Centerline Front and Bottom of Truck Pressure Coefficient......................... 41

Figure 33: Skin Friction Coefficient on Centerline and Around the Truck ....................... 42

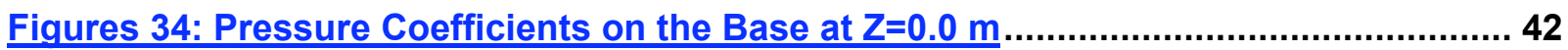

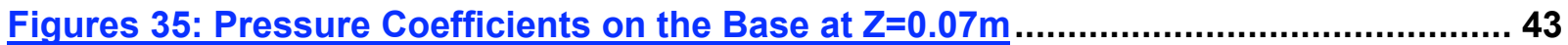

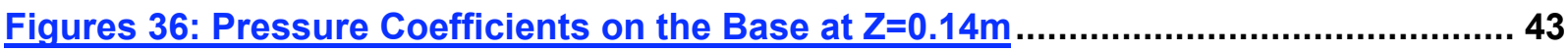

Figures 37 and 38: Contours of Negative U-Component of Velocity for SpalartAllmaras (left) and k-epsilon (right) Solutions on Medium Mesh

Figures 39 and 40: Pressure Coefficient Comparisons with Experiment on the Base (left) at $Z=0.0$ and Around the Centerline of the Truck (right) ..........................44

Figure 16: Iso-Surface for $u=-0.001$, coarse grid (left), medium grid (right), $10^{\circ}$ yaw. ...... 32

Figure 17: NASA Ames Experiment: GTS model installation top view (dimensions in inches).

Figure 18: GTS geometry and pressure tap locations. All measurements non-

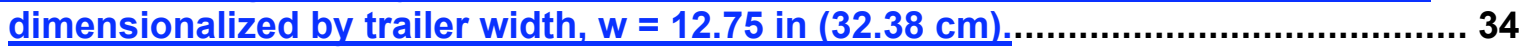

Figure 19: GTS model installation side view (dimensions in inches) .............................. 35

Figure 20: Schematic of a portion of the NASA $7 \times 10$ wind tunnel................................... 35

Figure 21: Boundary layer profile, NASA $7 \times 10$ test section centerline. .......................... 36

Figure 22: NASA $7 \times 10$ wind tunnel, pressure contours...............................................36

Figure 23: NASA $7 \times 10$ wind tunnel, center plane, Mach contours. ................................ 37

Figure 24: NASA $7 \times 10$ wind tunnel, Iso-Surface plot, u-component of velocity, u=89.92 m/s...... 37

Figure 25: NASA $7 \times 10$ wind tunnel, Iso-Surface plot, v-component of velocity,

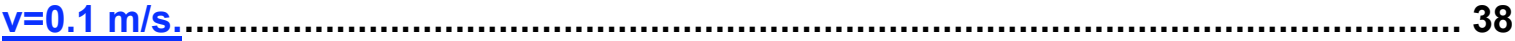

Figure 26: NASA $7 \times 10$ wind tunnel, Iso-Surface plot, w-component of velocity, w=-0.01 m/s....... 38

Figure 27: NASA 7x10 wind tunnel, Iso-Surface plot, pressure, $\mathrm{p}=97613 \mathrm{~Pa} \ldots \ldots \ldots \ldots . . . . . . . . .39$

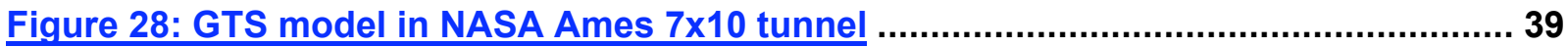

Figure 29: Medium mesh of the GTS model in NASA 7x10 tunnel ................................. 40

Figure 30: Mach Contours on Cutting Planes for Spalart-Allmaras Solution (Medium Mesh)....... 40

Figures 31: Centerline Front, Top of Truck Pressure Coefficient................................... 41

Figures 32: Centerline Front and Bottom of Truck Pressure Coefficient......................... 41

Figure 33: Skin Friction Coefficient on Centerline and Around the Truck ....................... 42

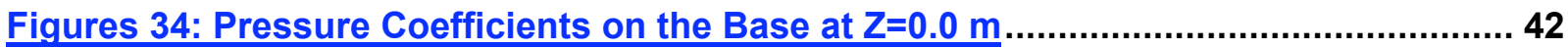

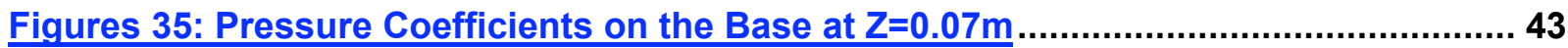

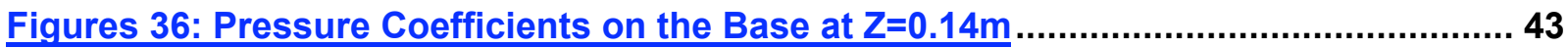

Figures 37 and 38: Contours of Negative U-Component of Velocity for SpalartAllmaras (left) and k-epsilon (right) Solutions on Medium Mesh ............................ 44

Figures 39 and 40: Pressure Coefficient Comparisons with Experiment on the Base (left) at $Z=0.0$ and Around the Centerline of the Truck (right) .......................... 44 


\section{List of Tables}

Table 1: PIV measurements for different plane orientations, locations and yaw angles 15

Table 2: Outflow static pressure calculation, coarse grid, 131 $551 \times 51$............................. 18

Table 3: Outflow static pressure calculation, medium grid, $191 \times 81 \times 81$ 18

Table 4: Outflow static pressure calculation, fine grid, $257 \times 129 \times 129$ 18

Table 5: Outflow static pressure for coarse, medium, and fine grids 19

Table 6: Comparison of predicted drag coefficient with NASA Ames experimental data 


\section{Introduction}

Sandia National Laboratories and Lawrence Livermore National Laboratory are part of a consortium funded by the Department of Energy to improve fuel efficiency of heavy vehicles (Class 8 trucks) by reducing aerodynamic drag. A typical Class 8 truck at $70 \mathrm{mph}$ uses $65 \%$ of its total energy expenditure to overcome aerodynamic drag. The drag of such vehicles can be reduced by a more aerodynamic tractor, integrating the tractor and the trailer, and applying add-on devices to reduce the total drag. The consortium is conducting validation experiments and state-of-the-art computational modeling and simulations to investigate and identify the key flow structures around the vehicle that are significantly contributing to the total drag. Examples of such flow structures are the complex flow field around the vehicle, the flow in the gap between the tractor and the trailer, and the flow at the base of the trailer. The consortium participants include Lawrence Livermore National Laboratory, Sandia National Laboratories, NASA Ames Research Center, University of Southern California, California Institute of Technology, Georgia Tech Research Institute, and Argonne National Laboratory.

A modern Class 8 tractor-trailer can weigh up to 80,000 pounds and has a windaveraged drag coefficient around $C_{D}=0.60$. At a typical highway speed of 70 miles per hour, about $65 \%$ of the total energy expenditure for a typical heavy truck goes to overcome the aerodynamic drag. To decrease the aerodynamic drag and reduce the fuel consumption for heavy vehicles the truck geometry must be altered. It is possible to reduce the drag coefficient of a present day truck by as much as $25 \%$

It is estimated that in the year 2012, Class 8 trucks will travel 60 billion highway miles per year [1]. For a typical Class 8 tractor-trailer powered by a modern, turbocharged diesel engine, reducing the drag coefficient by $25 \%$ would result in a total yearly savings of roughly 2 billion gallons of diesel fuel.

The aerodynamic design of heavy trucks is typically based on wind tunnel testing. Traditionally, no other methods have been available and the designers/aerodynamicists had achieved significant design improvements over the past several decades on the basis of limited quantitative information. Computer simulations of aerodynamic flow around heavy vehicles have significantly matured over the past five years and truck manufacturers are trying to integrate this new predictive capability into their vehicle aerodynamic design process.

Sandia's responsibility is to use computational fluid dynamics (CFD) codes to simulate the flow field around heavy vehicles and to predict the aerodynamic forces. In particular, Sandia is responsible for evaluating the use of Reynolds Averaged Navier-Stokes (RANS) methods to predict the aerodynamic forces on a simplified model of a tractor-trailer vehicle. If these techniques are successful, 
they can then be used to simulate the influence of add-on devices, such as a boattail plate on the base of the trailer, to investigate possible drag reduction benefits. If RANS methods are not adequately predictive, then a hybrid RANSLES approach will be investigated.

This report presents the steady RANS simulations performed on a generic tractor-trailer type geometry that was designed by Sandia National Laboratories and is known as the Ground Transportation System (GTS). Sandia's RANS code, SACCARA, was used to compute the flow around GTS. SACCARA will be discussed in the next section. Gutierrez et al. and Croll et al. [2, 3] give an overview of the GTS project and also provide details of the GTS geometry. The Spalart-Allmaras one-equation turbulence model is used for all the simulations except for one calculation for which the $\mathrm{k}-\square$ two-equation turbulence model was used.

Particular attention is given to validation of physical models by comparing the computational results to experimental data. Systematic mesh refinement studies are performed to obtain grid independent results. The validation effort is discussed in the next section. The GTS geometry was tested in the Texas A\&M University 7'x10' wind tunnel in May of 1995 [4] and also in the NASA Ames 7'x10' wind tunnel in February of 1999 [5]. Comparisons are made with data from both experiments. 


\section{Computational Methodology and Simulations}

\section{Computational Tool: SACCARA}

All computations are performed using the Sandia Advanced Code for Compressible Aerothermodynamics Research and Analysis code, SACCARA [68]. This code solves the compressible Navier-Stokes equations for subsonic through hypersonic flows. It employs a massively parallel, distributed-memory architecture based on multi-block structured grids. The code is capable of simulating axisymmetric, two-dimensional and three-dimensional flows using a cell-centered finite volume discretization. It has point implicit time integration schemes and several turbulence models. Ideal, equilibrium, and thermo-chemical nonequilibrium gas chemistry models are available. It also contains the options for ablating boundary conditions and rotating coordinate systems. The particular code options used for all the results presented in this report included: the implicit Lower-Upper Successive Gauss-Seidel LU-SGS scheme with a constant time step, second-order Yee's symmetric TVD scheme for advection and secondorder central differencing for the diffusion part of the NS equations, and no artificial smoothing. All simulations presented in this study have been performed using Sandia's teraflop computer ASCI-Red.

\section{Validation}

Validation of computational predictions is commonly performed by running a few simulations and comparing the results to experimental data. Typically, these simulations are performed without the full knowledge of experimental setup and conditions which could potentially alter the computational results. To improve on this procedure, all simulations in this study are performed with what is called a "validation simulation or calculation". With this approach, one begins with studying the experimental setup and the data to determine proper size and boundary conditions for the computational domain. It is critical for boundary condition information to be available from experimental data; however, if some key flow parameter is missing from the experimental data, such as the details of inflow, the calculation no longer can be labeled as a validation simulation. The reason is simple; the result of such a calculation can be manipulated with minor changes in the inflow boundary condition. Therefore, one of the important tasks in performing validation simulation is to establish accurate boundary conditions for the computational domain.

Sometimes, due to lack of documentation of an existing experiment some needed flow boundary condition may not be available, such as inflow turbulent intensities. In such cases, similar data may exist from some other experiment that was carried out in the same facility. Hence, validation simulation still can be carried out provided a sensitivity study of the parameter in question is performed. 


\section{Discussion of Experimental Conditions and SACCARA Results}

\section{Texas A\&M Experiment}

The ground transportation system (GTS) was tested in May of 1995 in the Texas A\&M wind tunnel. This tunnel is a closed circuit single return type facility with a nominally rectangular test section that is 7 feet high, 10 feet wide, and 12 feet long as shown in Figure 1. The test section corners have one-foot fillets to house fluorescent lamps to provide photographic lighting. Three-inch wide vertical venting slots in the sidewalls at the test section exit maintain near atmospheric static pressure in the test section. The test section sidewalls diverge about 1 inch in 12 feet to account for boundary layer growth. A turntable 7 feet in diameter built into the test section floor rotates with the external balance system to provide remote model positioning.

The experiment consisted of 85 runs acquiring aerodynamic force and moment data, surface pressure data, wake survey data, and flow visualization using smoke and yarn tufts, at yaw angles ranging from $-15^{\circ}$ to $+15^{\circ}$. Twelve GTS model configurations were tested; six with wheels on and six with wheels removed. The test also included the 5 - and 8 -foot ogive boattail add-ons, and $5^{\circ}$, $12.5^{\circ}$, and $30^{\circ}$ slant add-on devices. The objective of the Texas A\&M test was to develop a database on a generic model with various vehicle configurations that could be used to validate computational models. Detailed information about this experiment, including pressure tap locations, is discussed in references 2 and 3.

\section{GTS Flow Simulation Using Texas A\&M Wind Tunnel Data}

The Texas A\&M experimental data did not provide adequate tunnel information to establish proper boundary conditions for the computational domain. As a result, the contraction and the diffuser part of the tunnel were not modeled. Instead, the tunnel test section was extended upstream and downstream to construct the computational domain. Meshing the GTS model in the Texas A\&M 7'x10' wind tunnel proved to be a challenge. The difficulty came from the topology and the multi-block structured mesh that required point-to-point match up at zone interfaces. Several different approaches in handling the topology were investigated until a suitable solution was found. Subsequently, a volume mesh was generated (Fig. 2). At this point, mesh resolution requirements about the surface of GTS and the wake region needed to be determined.

Two-dimensional calculations were performed to investigate the temporal and the spatial resolution questions. It should be noted that the time and the length scales present in the 2-D and 3-D simulations are quite different; however, the $2-D$ results would provide a starting point to address the resolution issues in 3-D. 
A suitable 2-D grid was obtained by extracting a slice at the centerline of the test section from a 3-D volume grid. Several 2-D simulations were performed using the one-equation Spalart-Allmaras (SA) turbulence model with different mesh resolutions. Figures 3 and 4 show Mach and pressure contours around the GTS model, respectively. Figure 3 clearly shows the extent of the wake behind the trailer. The wake size is strongly influenced by the type of turbulence model being used and dimensionality of the problem. The 2-D simulations showed that the Spalart-Allmaras (SA) turbulence model was robust and not very sensitive to grid spacing near the wall. Given the results from the 2-D simulations, three volume grids, $0.5,4$, and 32 million points were constructed with minimum wall spacing of $\mathrm{y}^{+}=4,2$, and 1 for the coarse, medium and fine meshes, respectively.

Test run 31 from experimental data of Texas A\&M with baseline configuration with wheels removed was selected for computational simulation. Two yaw angles $0^{\circ}$ and $10^{\circ}$ were investigated. The flow conditions for this run were: Mach number 0.23 , Reynolds number $1.6 \times 10^{6}$ (based on trailer width), total pressure 103092.0 $\mathrm{N} / \mathrm{m}^{2}$, total temperature $298.44^{\circ} \mathrm{K}$, and atmospheric static pressure of $99,470.6$ $\mathrm{N} / \mathrm{m}^{2}$.

The boundary conditions were defined as follows: inflow - total pressure and temperature; outflow - prescribed static pressure (atmospheric); walls - tunnel floor and truck surface as no-slip and the rest as slip boundary condition and adiabatic condition on all the walls. Computational simulations were performed using the SA turbulence model with the coarse and medium meshes. At the time, computer file size limitations prevented use of the fine mesh. Therefore, only the coarse and medium mesh results will be presented.

Figure 5 shows the Mach contours for the medium grid solution at a vertical slice (yz-plane) behind the trailer at $0^{\circ}$ and $10^{\circ}$ yaw. It is clear from these figures that the presence of yaw angle significantly impacts the overall flowfield and the wake of the trailer. Figure 6 highlights the flowfield around GTS at a horizontal slice (xz-plane) mid-height. At $0^{\circ}$ yaw the flow remains attached around the tractor, however, at $10^{\circ}$ yaw the flow separates on the leeward side causing a separation bubble. Figure 7 shows a vertical slice (xy-plane) of the $10^{\circ}$ yaw solution at the centerline which, because of the yaw angle, cuts through part of the trailer. This figure also shows the flowfield at the top and the bottom of GTS, including the wake, at $0^{\circ}$ yaw. Figures 5-7 suggest that the complexity of the flowfield around GTS increases at higher angles. It also shows that there is some influence of the tunnel walls on the flow field at higher yaw angles. This supports the assumption that the tunnel walls should be included as part of the computational domain for validation simulations as was done in this study.

Figures 8 and 9 show the coarse and medium grid solutions on two yz-planes behind the trailer at $x=2.5 \mathrm{~m}$ and $x=3.25 \mathrm{~m}$ at $10^{\circ}$ yaw. Figures 10 and 11 show the coarse and medium mesh solutions on two xz-planes at $y=0.122 \mathrm{~m}$ and $\mathrm{y}=-$ $0.035 \mathrm{~m}$ at $10^{\circ}$ yaw. Figures 12 and 13 show the coarse and medium grid 
solutions on two $x y$-planes at $z=0.07 \mathrm{~m}$ and $z=0.215 \mathrm{~m}$ at $10^{\circ}$ yaw. It is clear that the coarse grid solution did not resolve the flowfield adequately around the tractor and in the base of the trailer near the corners and also in the wake. Additional grid levels are required for an adequate grid resolution study.

In these simulations, there are two distinct regions that responded significantly to increased grid resolution: the wake and the separated region on the leeward side of the tractor. Figure 14 shows streamlines that are colored by Mach number around the GTS model at $0^{\circ}$ yaw. The streamlines indicate that flow remains attached around the tractor and on the trailer as expected. Figure 15 highlights the flow field at $10^{\circ}$ yaw using streamlines similar to Fig. 14. At this yaw angle, there are two vortex-like structures that form on the upper and the lower sides of GTS due to geometry influences. The separation region on the leeward side is visible in this figure. Figure 16 presents an iso-surface of the u-component of velocity equal to $-0.001 \mathrm{~m} / \mathrm{s}$. This shows the separation region for the coarse and medium grid solutions. The size, location, and the shape of the separated region changed significantly between the coarse and medium meshes. The coarse mesh solution predicts the separated region farther downstream on the leeward side of the tractor away from the vertical radii. The medium mesh solution predicts the separation to be much closer to the vertical radii of the tractor that is more physically meaningful. Again, this should underscore the importance of a grid resolution study.

The pressure tap data was not compared to since the location of the reference pressure was not reported in the experimental data. This location plays a key role in comparing the computed results to the experimental data and an incorrect reference pressure location can alter the magnitude and the behavior of the pressure coefficient distribution on the surface of GTS. Without a reference pressure comparisons could not be made between the computed pressure coefficient on the surface of GTS to experimental data.

The results presented above should be viewed as preliminary and qualitative. Further evaluation of the Texas A\&M data was not pursued because the NASA Ames experimental data became available and it provided more detailed information concerning the tunnel conditions and the flow field. The next section describes the NASA Ames experiment and the simulations that were performed using that data set.

\section{NASA Ames Experiment}

The GTS model was studied experimentally in the NASA Ames $7{ }^{\prime} \times 10^{\prime}$ wind tunnel in February of 1999. The experimental measurements included axial force (drag), surface pressures, surface hot-film anemometry, oil-film interferometry, and 3-D particle image velocimetry (PIV). Oil film interferometry provided quantitative measurements of skin friction and qualitative oil flow images. 
Detailed information about this experiment can be found in reference NASA/TM2001-209621 titled: "An Experimental Study of the Ground Transportation System (GTS) Model in the NASA Ames 7- by 10-Ft Wind Tunnel." [5]

The NASA Ames 7'x10' wind tunnel has a 15 feet $(4.57 \mathrm{~m})$ long test section with a constant height of 7 feet $(2.13 \mathrm{~m})$ and a nominal width of 10 feet $(3.05 \mathrm{~m})$ with a $1 \%$ wall divergence. The boundary layer thickness at the test section is 2.1 in $(5.3 \mathrm{~cm})$ which corresponds to a displacement thickness of 0.6 in $(1.5 \mathrm{~cm})$. The boundary layer profile at the test section is provided. The empty tunnel (test section) turbulence intensities $(\mathrm{u}, \mathrm{v}, \mathrm{w})$ were $0.1 \%, 0.3 \%$, and $0.3 \%$, respectively, at a test condition of Mach 0.22 . These turbulence levels correspond to an RMS turbulence intensity of $0.25 \%$ and a turbulence factor of 1.2 .

Figure 17 shows the dimensions of the GTS model non-dimensionalized by the trailer width of 12.75 in $(32.385 \mathrm{~cm})$. The model was instrumented with a total of 79 pressure taps as shown in Figure 18. A tabular list of the tap locations is available from Ref. [5]. The GTS model was positioned 5.25 in $(13.33 \mathrm{~cm})$ downstream of the beginning of the test section as shown in Figure 17. The bottom of the model was located 3.0 in $(7.6 \mathrm{~cm})$ above the wind tunnel floor. Four cylindrical struts connected the model to the scale system and 1.5 in (3.8 $\mathrm{cm}$ ) OD cylindrical fairings (non-metric) extend from the floor to within 0.25 in $(0.63 \mathrm{~cm})$ of the bottom of the model.

The location of the three rows of pressure taps mounted on the test-section wall is shown in Fig. 19. The test section static pressure was computed from a single wall pressure tap located at $\mathrm{x} / \mathrm{w}=4.5, \mathrm{y} / \mathrm{w}=2.6$, and $\mathrm{z} / \mathrm{w}=-4.7$ as shown in Figure 19.

Three-component Particle Image Velocimetry (PIV) measurements were conducted for several plane orientations as shown in Table 1. PIV images for both instantaneous and time averaged flowfield are available from the report.

Table 1: PIV measurements for different plane orientations, locations and yaw angles

\begin{tabular}{|l|l|l|l|}
\hline Orientation & Location & Yaw, deg. & $\operatorname{Re} / 10^{6}$ \\
\hline Horizontal & $\mathrm{y} / \mathrm{w}=0.35,0.70,1.05$ & 0,10 & $2.0,0.74,0.3$ \\
\hline Cross-stream & $\mathrm{x} / \mathrm{w}=8.0,8.35,8.78$ & 0,10 & $2.0,0.74$ \\
\hline Streamwise & $\mathrm{z} / \mathrm{w}=0$ & 0 & $2.0,0.74$ \\
\hline
\end{tabular}




\section{Determination of Boundary Conditions for Computational Domain}

The NASA Ames experiment provides all the necessary data to establish proper boundary conditions for the simulations. To conduct the validation simulations, part of the NASA Ames 7'x10' wind tunnel was modeled that including part of the contraction section, the full test section, and part of the diffuser section as shown in Fig 20. Modeling the tunnel is important for the following reasons:

- It avoids working with corrected tunnel data

- It properly captures the incoming boundary layer to the test section. This is important since the GTS model is mounted 3 inches above the ground plane, and from tunnel data, the incoming boundary layer to the test section is about 2 inches.

- It computes a pressure coefficient from calculated results that is consistent with experiment. This requires that the computation and experiment use the same reference pressure. In the NASA experiment, the reference pressure was measured on the tunnel sidewall as shown in Fig. 19.

- It establishes consistent flow conditions in the test section.

In order to model the NASA Ames 7'x10' tunnel, the blueprints for the part of the tunnel that included the test section were obtained. CAD surfaces were constructed using the blue prints and several meshes were generated. The settling chamber was included in one of the meshes.

The computational domains for the tunnel are shown in Figure 20. For inflow boundary conditions, stagnation pressure and temperature were specified and the inflow velocity profile was allowed to develop. The tunnel floor was modeled as a no-slip surface and the rest of the walls as slip surfaces. The subsonic outflow boundary condition located at the diffuser section of the tunnel requires a static pressure. Unfortunately, there was no experimentally measured static pressure at the outflow boundary. The test section static pressure was used as a guide to adjust the static pressure at the outflow boundary. The tunnel empty test section static pressure, which was calculated from calibration data, was provided by the NASA experiment at the center of the turntable at mid-height. Trial and error was used to establish the outflow static pressure that matched the tunnel empty test section static pressure and Mach number. Typically, four to six tunnel simulations were necessary to obtain a static pressure for the outflow.

In order to model the tunnel simulations the boundary layer profile at the entrance to the test section was needed as well as the static pressure at the outflow boundary was needed. The NASA experimental data showed that the measured boundary layer profile is not sensitive to the tunnel dynamic pressure. Given this characteristic, the tunnel boundary layer profile can be simulated with little impact to the calculation of outflow static pressure. Hence, flow simulations 
were performed to match the boundary layer profile at the entrance to the test section and then additional flow simulations were performed to obtain the static pressure at the outflow boundary.

In all the tunnel simulations, the Spalart-Allmaras (SA) one-equation turbulence model was used with the assumption that the flow was fully turbulent. There was no attempt to model transition. Three different mesh sizes, $131 \times 51 \times 51$, $191 \times 81 \times 81$, and $257 \times 129 \times 129$, were used in these simulations. Initially the settling chamber was included as part of the computational domain. After several calculations, it was apparent that only part of the converging section (Fig. 20) is needed to properly capture the incoming boundary layer profile to the test section. Figure 21 shows the computed boundary layer profile based on the fine grid calculation compared to the experimental data. The comparison is reasonable. Figure 22 shows the pressure variation on the tunnel walls and Fig. 23 shows the Mach contours at a plane through the mid-section of the tunnel. In this figure, the boundary layer is visible on the ground plane.

The data from these tunnel simulations also provided an opportunity to examine the flow quality in the tunnel test section. Figure 24 shows the iso-surface plot of u-component of velocity at $u=89.92 \mathrm{~m} / \mathrm{s}$ (Mach $=0.27$ ), the target flow speed in the test section. This figure clearly shows that uniform flow exists above the turntable. Similarly, Figure 25 shows the iso-surface plot of the v-component of velocity at $v=0.1 \mathrm{~m} / \mathrm{s}$. There exists a positive $v$-component of velocity near the side walls in the test section; the magnitude diminishes moving toward the centerline. Figure 26 shows the iso-surface plot for the $\mathrm{w}$-component of velocity at $w=-0.01 \mathrm{~m} / \mathrm{s}$. This figure shows the presence of a 3-dimensional boundary layer in the test section. Figure 27 shows the iso-surface plot for pressure at $97613 \mathrm{~Pa}$., the target static pressure mid-height above the center of the turntable. Based on these results it was assumed that the flow in the test section, above the turntable, is uniform and acceptable for testing.

Iterative steps were taken to determine an acceptable static pressure to apply at the outflow boundary. Run number 7 was selected for comparison. A sweep of yaw angle points was run from $-14^{\circ}$ to $14^{\circ}$. The following information is given for this run: Mach number 0.27 , Reynolds number $2 \times 10^{6}$ (based on trailer width) dynamic pressure $105.2 \mathrm{psf}\left(5,037.18 \mathrm{~N} / \mathrm{m}^{2}\right)$, total pressure $14.888 \mathrm{psia}$ $\left(102,652.76 \mathrm{~N} / \mathrm{m}^{2}\right)$, total temperature $41.6^{\circ} \mathrm{F}\left(282.06{ }^{\circ} \mathrm{K}\right)$, and tunnel empty test section static pressure (at turntable center, mid-height) 14.157 psia $(97,612.515$ $\mathrm{N} / \mathrm{m}^{2}$ ). Based on an assumed outflow static pressure, a steady state solution was obtained on each grid. The solution was probed at the center of the turntable mid-height for all flow parameters. The solution was considered acceptable if the computed test section static pressure was within $1 \mathrm{~Pa}$ of the experimental data.

Tables 2-4 show the runs for the coarse, medium, and fine grids, respectively. Table 5 shows the accepted runs for all three grids. The outflow static pressure shows convergent behavior for the coarse and medium mesh but not the fine 
mesh. This was surprising and obviously something was slightly different with the fine mesh calculation. This change was not visually detectable from the other two solutions and needs further investigation. The variation in outflow static pressure from the coarse to the fine mesh is about $0.04 \%$ that resulted in $0.02 \%$ variation in the u-component of velocity in the test section. All three static pressures were within the experimental uncertainty range. Since there was a question about the fine mesh solution, the outflow static pressure for the medium mesh was selected for all of the GTS simulations.

Table 2: Outflow static pressure calculation, coarse grid, 131x51x51

\begin{tabular}{|l|l|l|l|l|l|}
\hline $\begin{array}{l}\text { Outflow } \\
\text { Static } \\
\text { Pressure, } \\
\text { Pa }\end{array}$ & $\begin{array}{l}\text { Test } \\
\text { section } \\
\text { static } \\
\text { pressure, } \\
\text { Pa }\end{array}$ & $\begin{array}{l}\text { u-component } \\
\text { of velocity, } \\
\mathbf{m} / \mathbf{s}\end{array}$ & $\begin{array}{l}\text { Mach } \\
\text { number }\end{array}$ & $\begin{array}{l}\text { Test section } \\
\text { static } \\
\text { temperature, } \\
\text { K }\end{array}$ & $\begin{array}{l}\text { Test } \\
\text { section } \\
\text { density, } \\
\mathbf{k g} / \mathbf{m}^{\mathbf{3}}\end{array}$ \\
\hline $100,124.00$ & $97,602.5$ & 90.027 & 0.269 & 278.025 & 1.223 \\
\hline $100,130.00$ & $97,614.7$ & 89.916 & 0.269 & 278.035 & 1.223 \\
\hline $100,129.14$ & $97,613.0$ & 89.931 & 0.269 & 278.033 & 1.223 \\
\hline
\end{tabular}

Table 3: Outflow static pressure calculation, medium grid, 191x81x81

\begin{tabular}{|l|l|l|l|l|l|}
\hline $\begin{array}{l}\text { Outflow } \\
\text { Static } \\
\text { Pressure, } \\
\text { Pa }\end{array}$ & $\begin{array}{l}\text { Test } \\
\text { section } \\
\text { static } \\
\text { pressure, } \\
\text { Pa }\end{array}$ & $\begin{array}{l}\text { u-component } \\
\text { of velocity, } \\
\mathbf{m} / \mathbf{s}\end{array}$ & $\begin{array}{l}\text { Mach } \\
\text { number }\end{array}$ & $\begin{array}{l}\text { Test section } \\
\text { static } \\
\text { temperature, } \\
\text { K }\end{array}$ & $\begin{array}{l}\text { Test } \\
\text { section } \\
\text { density, } \\
\mathbf{k g} / \mathbf{m}^{3}\end{array}$ \\
\hline $100,129.14$ & $97,399.9$ & 90.066 & 0.269 & 278.022 & 1.223 \\
\hline $100,134.00$ & $97,608.8$ & 89.986 & 0.269 & 278.029 & 1.223 \\
\hline $100,135.00$ & $97,610.7$ & 89.970 & 0.269 & 278.031 & 1.223 \\
\hline $100,136.00$ & $97,613.5$ & 89.943 & 0.269 & 278.033 & 1.223 \\
\hline
\end{tabular}

Table 4: Outflow static pressure calculation, fine grid, 257×129x129

\begin{tabular}{|l|l|l|l|l|l|}
\hline $\begin{array}{l}\text { Outflow } \\
\text { Static } \\
\text { Pressure, } \\
\text { Pa }\end{array}$ & $\begin{array}{l}\text { Test } \\
\text { section } \\
\text { static } \\
\text { pressure, } \\
\mathbf{P a}\end{array}$ & $\begin{array}{l}\text { u-component } \\
\text { of velocity, } \\
\mathbf{m} / \mathbf{s}\end{array}$ & $\begin{array}{l}\text { Mach } \\
\text { number }\end{array}$ & $\begin{array}{l}\text { Test section } \\
\text { static } \\
\text { temperature, } \\
\mathbf{K}\end{array}$ & $\begin{array}{l}\text { Test } \\
\text { section } \\
\text { density, } \\
\mathbf{k g} / \mathbf{m}^{3}\end{array}$ \\
\hline $100,138.20$ & $97,551.4$ & 90.512 & 0.271 & 277.982 & 1.222 \\
\hline $100,148.00$ & $97,571.2$ & 90.333 & 0.270 & 277.998 & 1.222 \\
\hline $100,160.00$ & $97,605.1$ & 90.027 & 0.269 & 278.026 & 1.223 \\
\hline $100,168.00$ & $97,613.1$ & 89.953 & 0.269 & 278.032 & 1.223 \\
\hline
\end{tabular}


Table 5: Outflow static pressure for coarse, medium, and fine grids

\begin{tabular}{|l|l|l|l|l|l|l|}
\hline Grid & $\begin{array}{l}\text { Outflow } \\
\text { Static } \\
\text { Pressure, } \\
\mathbf{P a}\end{array}$ & $\begin{array}{l}\text { Test } \\
\text { section } \\
\text { static } \\
\text { pressure, } \\
\mathbf{P a}\end{array}$ & $\begin{array}{l}\text { u-component } \\
\text { of velocity, } \\
\mathbf{m} / \mathbf{s}\end{array}$ & $\begin{array}{l}\text { Mach } \\
\text { number }\end{array}$ & $\begin{array}{l}\text { Test section } \\
\text { static } \\
\text { temperature, } \\
\mathbf{K}\end{array}$ & $\begin{array}{l}\text { Test } \\
\text { section } \\
\text { density, } \\
\mathbf{k g} / \mathbf{m}^{\mathbf{3}}\end{array}$ \\
\hline Coarse & $100,129.14$ & $97,613.0$ & 89.931 & 0.269 & 278.033 & 1.223 \\
\hline Medium & $100,136.00$ & $97,613.5$ & 89.943 & 0.269 & 278.033 & 1.223 \\
\hline Fine & $100,168.00$ & $97,613.1$ & 89.953 & 0.269 & 278.032 & 1.223 \\
\hline
\end{tabular}

\section{GTS Flow Simulations Using NASA Ames Wind Tunnel Data}

Based on the results of the simulations of the GTS model in the Texas A\&M wind tunnel, two grids were constructed for the GTS model in the NASA Ames wind tunnel. The grids have approximately $4-$ and 12 -million points with minimum wall spacing of $\mathrm{y}^{+}=2$ and 1 for the coarse and medium meshes, respectively. The selected values of $\mathrm{y}^{+}$were assumed to be appropriate for use with the SA turbulence model that, in the $2 \mathrm{D}$ studies, did not show sensitivity to variation of $\mathrm{y}^{+}$less than 5 . Figure 28 shows the GTS model in the test section of the NASA Ames $7 \times 10$ wind tunnel and Fig. 29 shows the surface mesh for the medium grid that includes the GTS and tunnel walls. Tunnel empty simulations also provide the necessary boundary conditions to establish proper flow condition in the tunnel test section.

From the available experimental data runs, run 7 and sweep 9 was selected. The following flow conditions were provided for this run: Mach number 0.28 , velocity $93.91 \mathrm{~m} / \mathrm{s}$, dynamic pressure $5314.89 \mathrm{~N} / \mathrm{m}^{2}$, Reynolds number $2.08 \times 10^{6}$ (based on trailer width), total pressure $102649.2 \mathrm{~N} / \mathrm{m}^{2}$, total temperature $284.5^{\circ} \mathrm{K}$, static pressure $97339.1 \mathrm{~N} / \mathrm{m}^{2}$, static temperature $280.2^{\circ} \mathrm{K}$, and air density $1.206 \mathrm{~kg} / \mathrm{m}^{3}$. Simulations were performed for $0^{\circ}$ yaw using the coarse and medium meshes with the SA turbulence model. Figure 30 highlights the flow field around GTS using Mach contours for the medium mesh. These figures present a similar flow field that was computed for GTS in the Texas A\&M wind tunnel simulations as shown in Figures 5-7. 
The surface pressure coefficient $C_{p}$ was computed using a reference pressure located on the wall, as was described above in the NASA experimental section, for each of the solutions. The reference static wall-pressure $p_{r}$ was used to calculate pressure coefficients as follows

$$
C_{p}=\frac{p \square p_{r}}{q}
$$

where the tunnel dynamic pressure $q$ was calculated as the difference between the settling-chamber static pressure and the reference wall-pressure.

Figures 31 and 32 show the computed pressure coefficient and the experimental data along the front, top and bottom of the GTS at centerline for coarse and medium mesh. Both solutions show reasonable agreement with the experimental pressure coefficient along the front, top and bottom of the center of the truck. Figure 33 shows the computed skin friction coefficient on the centerline of the truck for the coarse and medium meshes compared to the experimental data. The flow transitions from laminar to turbulent on the top of the tractor as is shown by the experimental data. In all simulations, flow is assumed to be fully turbulent and transition was not modeled. The difference in the skin friction behavior on the top of the tractor between the coarse and medium mesh is assumed to be due to the sensitivity of the turbulence model to the mesh resolution.

Figures 34-36 show pressure coefficients on the base of the vehicle at the centerline and at two other locations between the edge of the truck and the centerline. Neither solution shows very good agreement with the experimental data. In addition, the trends are completely different compared to the timeaveraged results from experimental data.

An additional solution using the $\mathrm{k}-\mathrm{C}$ turbulence model was obtained for the medium mesh. This solution did not completely converge due to problems with the restart capability in the parallel version of the code. Figures 37 and 38 show iso-surfaces for the u-component of velocity of -0.001 for both the SA and k- $\square$ solutions. The length of the recirculation region is about $0.4 \mathrm{~m}$ for the SA solution and about $0.7 \mathrm{~m}$ for the $\mathrm{k}-\square$ solution. This clearly indicates how sensitive the solution is to the choice of the turbulence model. Figure 39 shows a comparison of the pressure just behind the trailer for both the SA and the k- $\square$ solutions. The k$\square$ solution predicts higher pressures at the base compared to the SA solutions. The differences in the SA solutions are due to grid resolution. The medium mesh has more points near the edges of the base of the truck and it should do a better job of resolving the flow gradients.

Table 5 shows the experimentally measured and computed drag coefficients. The experimental drag coefficients were measured using two different dynamic pressures that were calculated from two different reference static pressures. In Table 5, the subscript $W$ refers to the static pressure measured on the test- 
section tunnel wall and the subscript $R$ refers to the static pressure measured upstream of the test section. The drag coefficients obtained from the simulations are based on the dynamic pressure calculated using the test section dynamic pressure quoted in Reference 3 for Run 7. Both the SA and $k-\square$ model significantly over-predicted the drag. The RANS approach with these turbulence models clearly has difficulty predicting the flow structure in the wake of the trailer. This does not mean that other more advanced turbulence models would have the same difficulty predicting the flow structure in the wake. Excluding the wake of the trailer, RANS did a reasonable job in predicting the flow field around GTS compared to the experimental data. However, if absolute drag is of interest other turbulence models should be investigated.

Table 6: Comparison of predicted drag coefficient with NASA Ames experimental data

\begin{tabular}{|c|c|c|c|}
\hline Model & Mesh & $C_{D}$ & $\%$ Error \\
\hline SA & Coarse & 0.379 & 44 \\
\hline SA & Medium & 0.418 & 59 \\
\hline k- $\square$ & Medium & 0.318 & 21 \\
\hline \multicolumn{2}{|c|}{$\begin{array}{l}\text { NASA Ames experiment, } \\
C_{D, R}\end{array}$} & 0.263 & \\
\hline \multicolumn{2}{|c|}{$\begin{array}{l}\text { NASA Ames experiment, } \\
C_{D, W}\end{array}$} & 0.249 & \\
\hline
\end{tabular}




\section{Conclusions and Recommendations for Future Work}

The flow field around the Ground Transportation System (GTS) has been investigated by modeling and simulation using steady RANS. To validate the computed results the Texas A\&M and the NASA Ames wind tunnel data were utilized. Initially, the Texas A\&M experiment was considered for simulations at $0^{\circ}$ and $10^{\circ}$ yaw with two different grid resolutions. Four simulations were performed using steady RANS with the Spalart-Allmaras turbulence model. Unfortunately, the computed results could not be compared to the experimental data due to: 1) lack of PIV data for flow visualization; and 2) lack of documentation for a reference pressure and its location that is needed to evaluate the pressure coefficients. To have a meaningful comparison of the pressure coefficient distribution on the body of the GTS model between the computed and experimental data the reference pressure location must be the same. However, the simulation results provided guidance for grid resolution and overall insight into the behavior of the flow.

The NASA Ames experiment provided detailed flow measurements, such as PIV, as was discussed above. In addition, wind tunnel data was provided to establish the proper boundary conditions for validation simulations. Tunnel empty simulations were performed to obtain the static pressure needed for the outflow boundary condition. An accurate determination of the boundary conditions is essential in conducting a validation calculation. Simulations for the GTS model at $0^{\circ}$ yaw angle were performed using two different grid sizes using both the Spalart-Allmaras and the k- $\square$ turbulence models. The solutions with the SA turbulence model converged to machine zero, however, the medium mesh k- $\square$ solution did not fully converged due to problems with the code's restart capability. All of the solutions significantly over-predicted the total drag. It is interesting that the grid resolution for the SA model shows an incorrect trend for drag, for example, the predicted drag coefficient for the medium mesh solution is worse than the coarse grid solution. The SA model drag prediction was off by as much as $59 \%$. The $\mathrm{k}-\square$ model showed better agreement with the drag coefficient compared to the SA model. This could be attributed to the behavior of the turbulence model in the wake of the trailer.

Overall, steady RANS with the SA model reasonably predicted the flow field around the GTS model but had difficulty with predicting the wake of the trailer. The one k- $\square$ model solution suggests that other more sophisticated turbulence models such as Wilcox k- $\square$, Menter SST, and Durbin V2f model could improve the wake predictions. 


\section{Acknowledgments}

The authors thank Walter Gutierrez, Basil Hassan, and Walter Rutledge for the fruitful discussions during the course of this investigation. The authors also sincerely thank Jeffery Payne for his assistance with code modification regarding domain decomposition and the flow solver. The authors would like to thank Dr. Sidney Diamond and Dr. Jules Routbort from the DOE Office of Energy Efficiency and Renewable Energy, Office of FreedomCar and Vehicle Technologies. This work was carried out during the years 2000-2001 at Sandia National Laboratories in Albuquerque, New Mexico. 


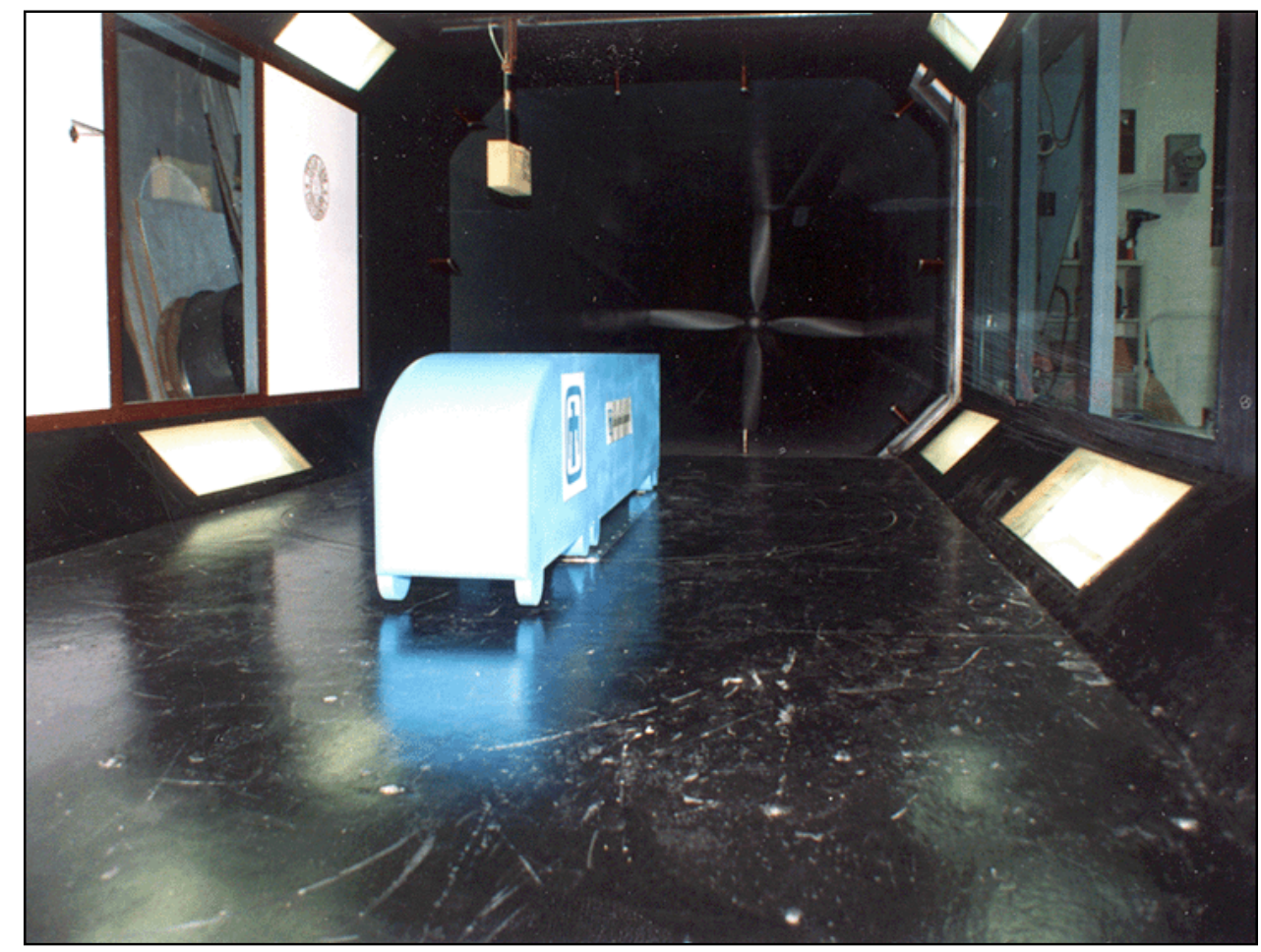

Figure 1: GTS model in Texas A\&M 7'x10' wind tunnel.

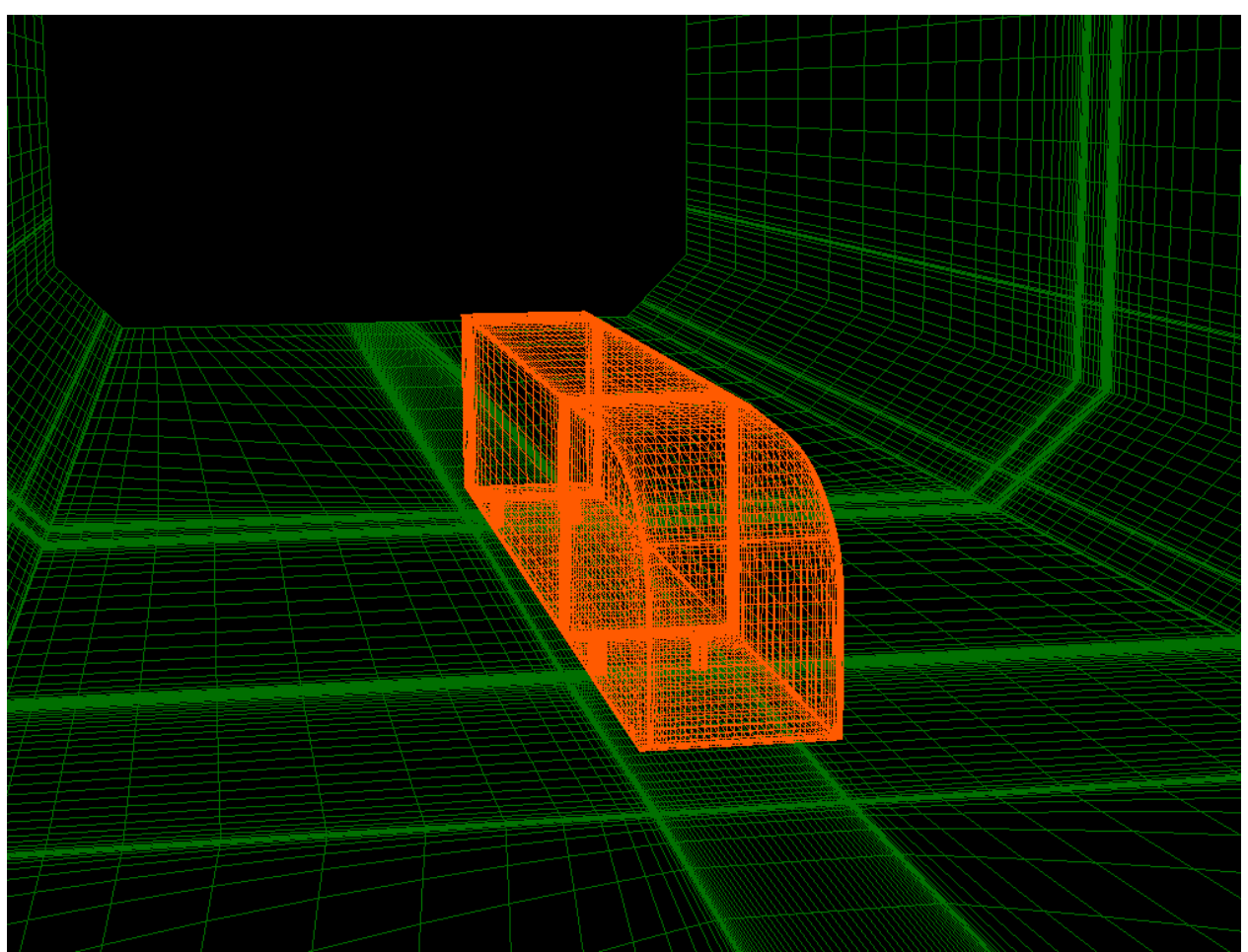

Figure 2: Coarse mesh of GTS model in Texas A\&M 7'x10' wind tunnel. 


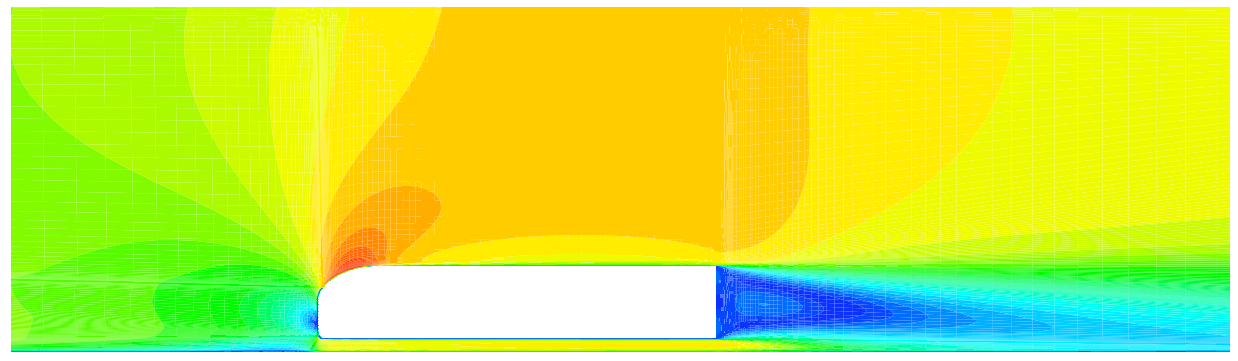

Figure 3: GTS flow simulation, 2-D, Mach contours

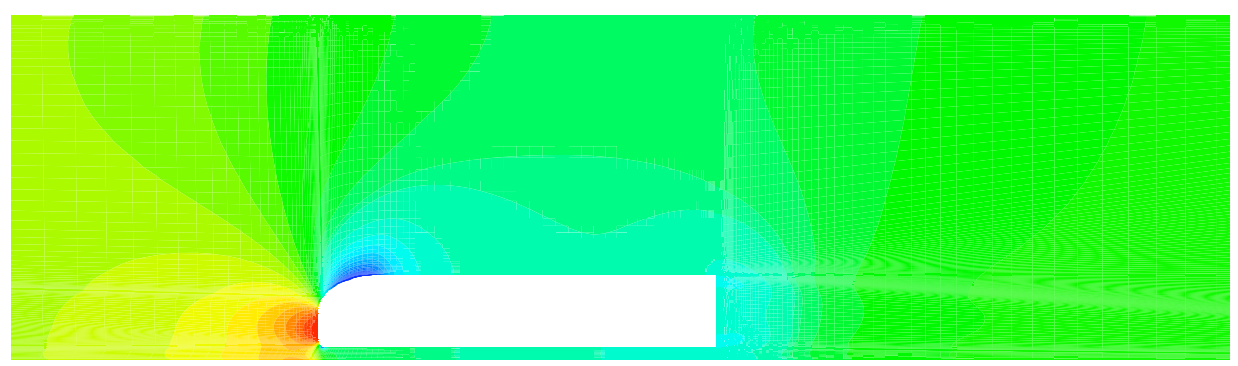

Figure 4: GTS flow simulation, 2-D, pressure contours 

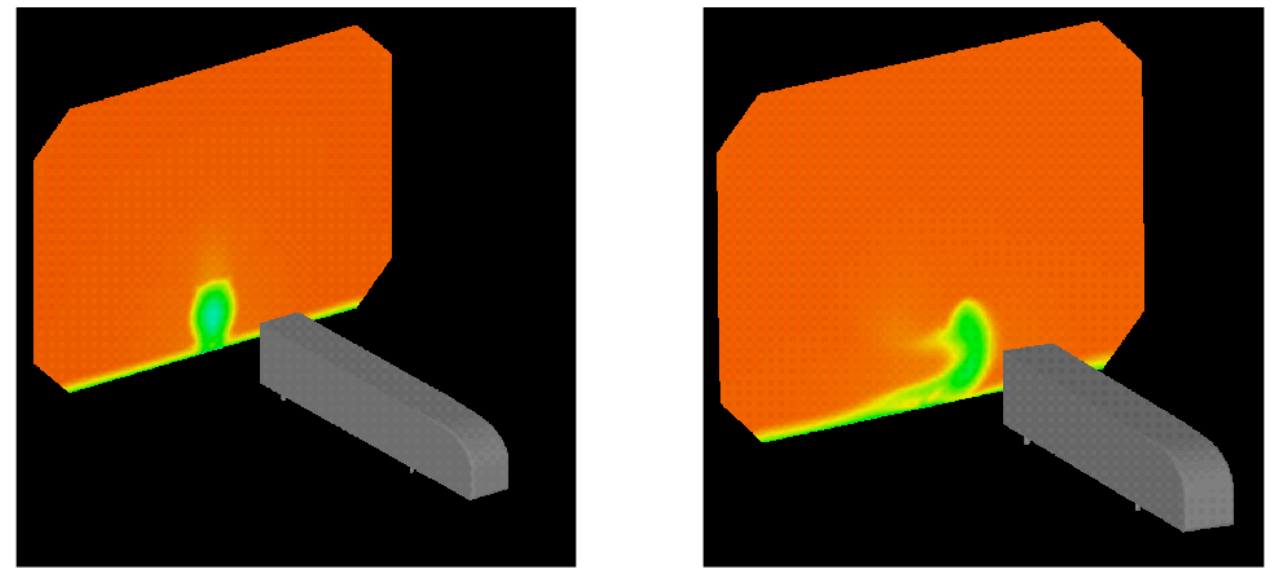

Figure 5: Mach contour, yz slice, $0^{\circ}$ yaw (left), $10^{\circ}$ yaw (right).
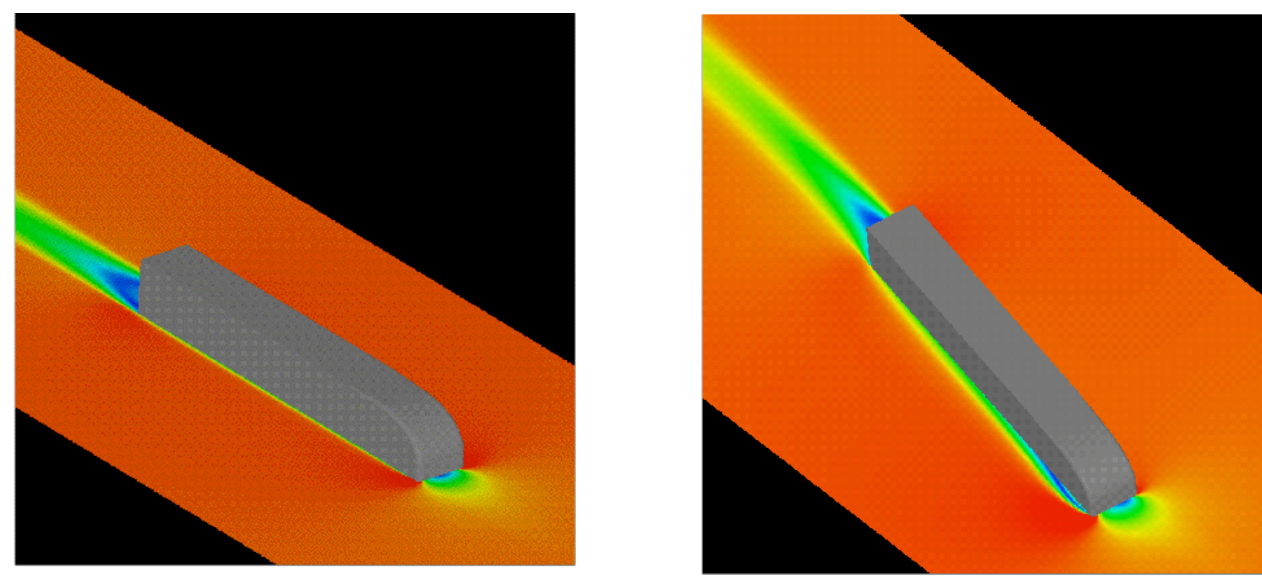

Figure 6: Mach contour, xz slice, $0^{\circ}$ yaw (left), $10^{\circ}$ yaw (right).
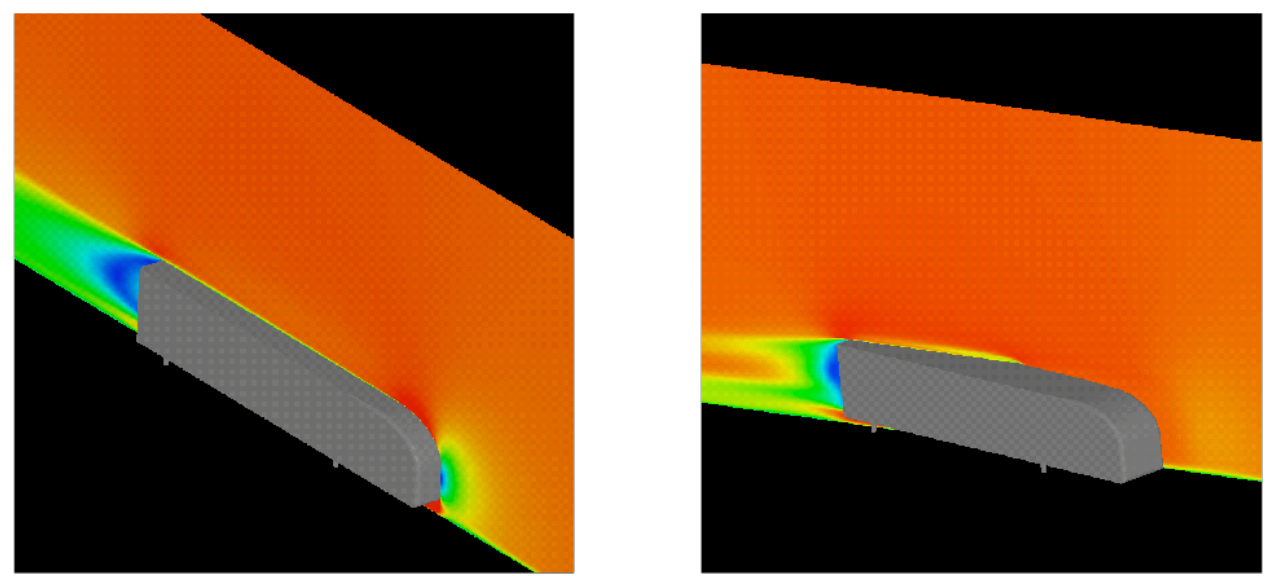

Figure 7: Mach contour, xy slice, $0^{\circ}$ yaw (left), $10^{\circ}$ yaw (right). 

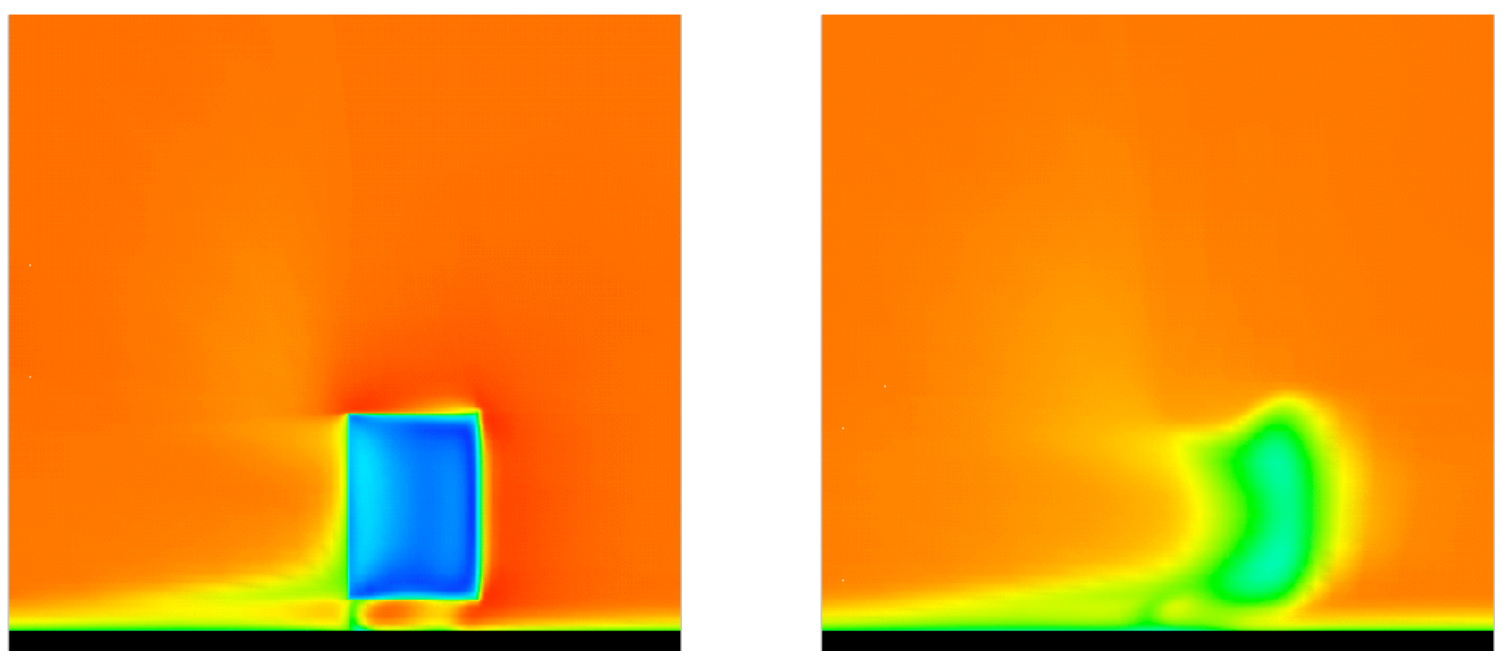

Figure 8: Mach contour, yz slice, $x=2.5 \mathrm{~m}$ (left), $\mathrm{x}=3.25 \mathrm{~m}$ (right), $10^{\circ}$ yaw, coarse grid.
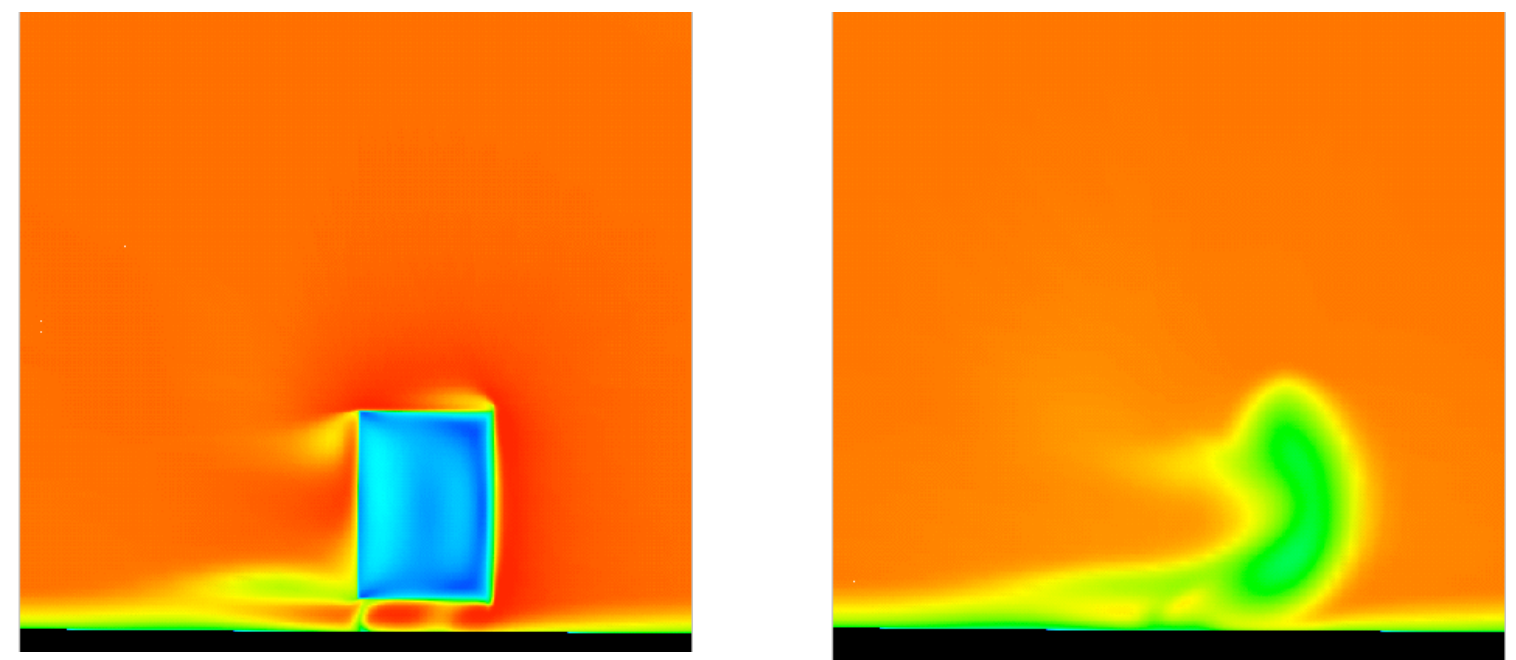

Figure 9: Mach contour, yz slice, $x=2.5 \mathrm{~m}$ (left), $x=3.25 \mathrm{~m}$ (right), $10^{\circ}$ yaw, medium grid. 

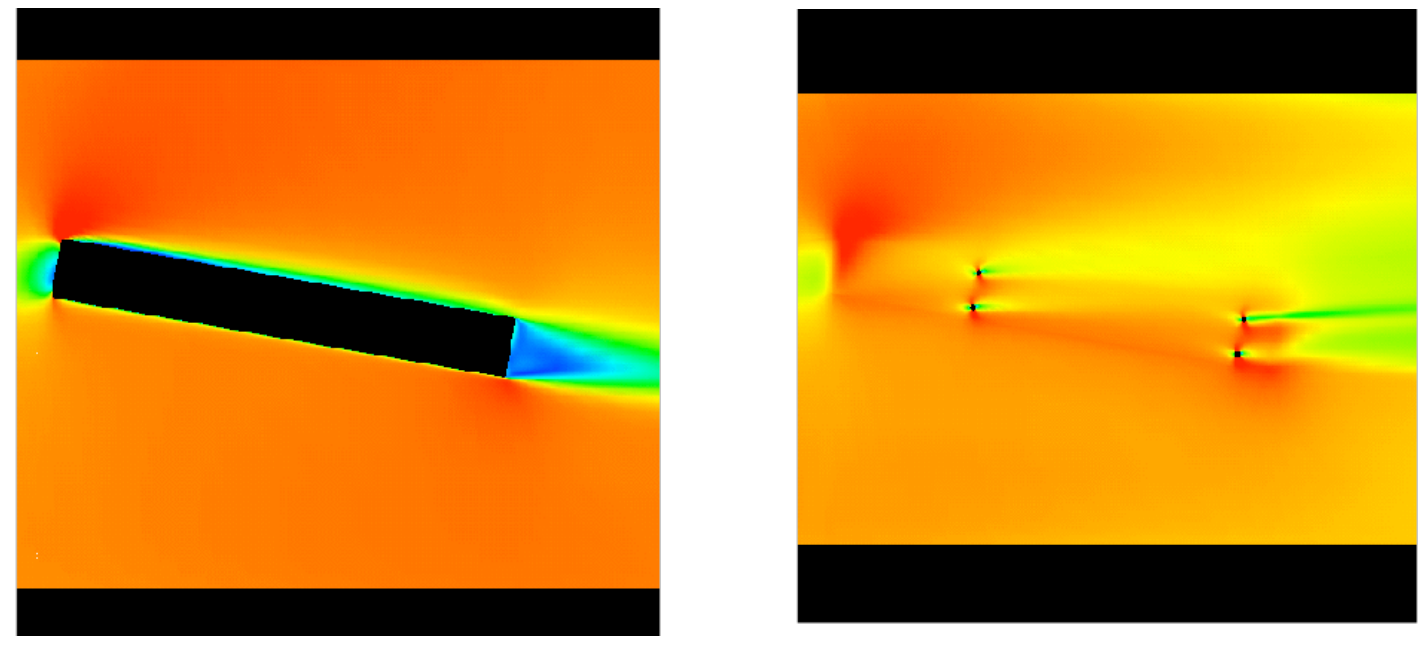

Figure 10: Mach contour, $x z$ slice, $y=0.122 \mathrm{~m}$ (left), $y=-0.035 \mathrm{~m}$ (right), $10^{\circ}$ yaw, coarse grid.
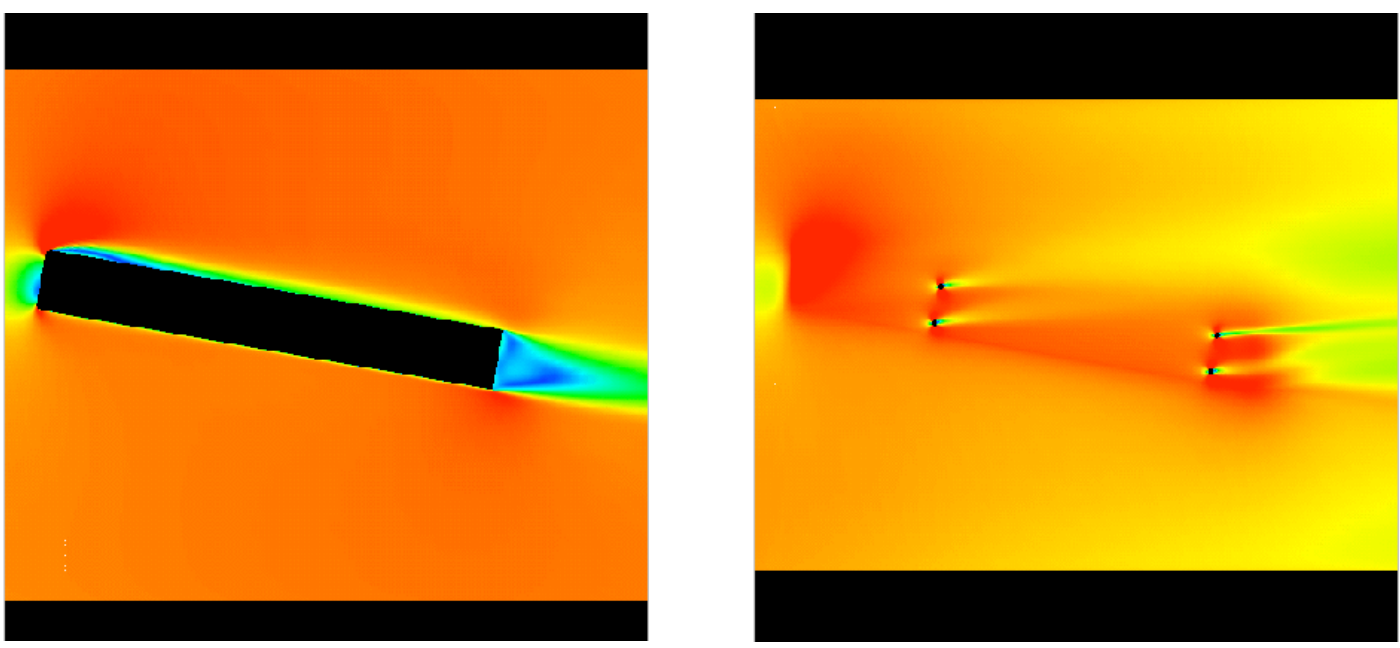

Figure 11: Mach contour, $x z$ slice, $y=0.122 \mathrm{~m}$ (left), $y=-0.035 \mathrm{~m}$ (right), $10^{\circ}$ yaw, medium grid. 

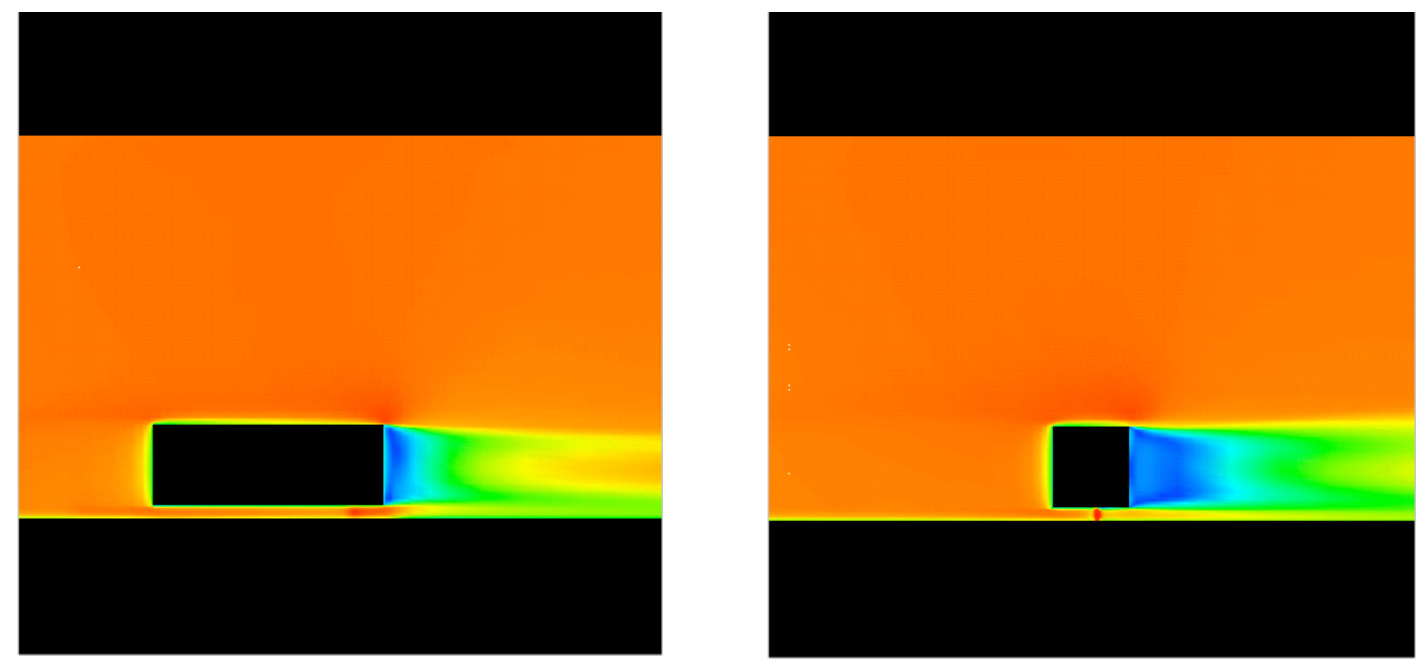

Figure 12: Mach contour, $x y$ slice, $z=0.07 \mathrm{~m}$ (left), $z=0.215 \mathrm{~m}$ (right), $10^{\circ}$ yaw, medium grid.
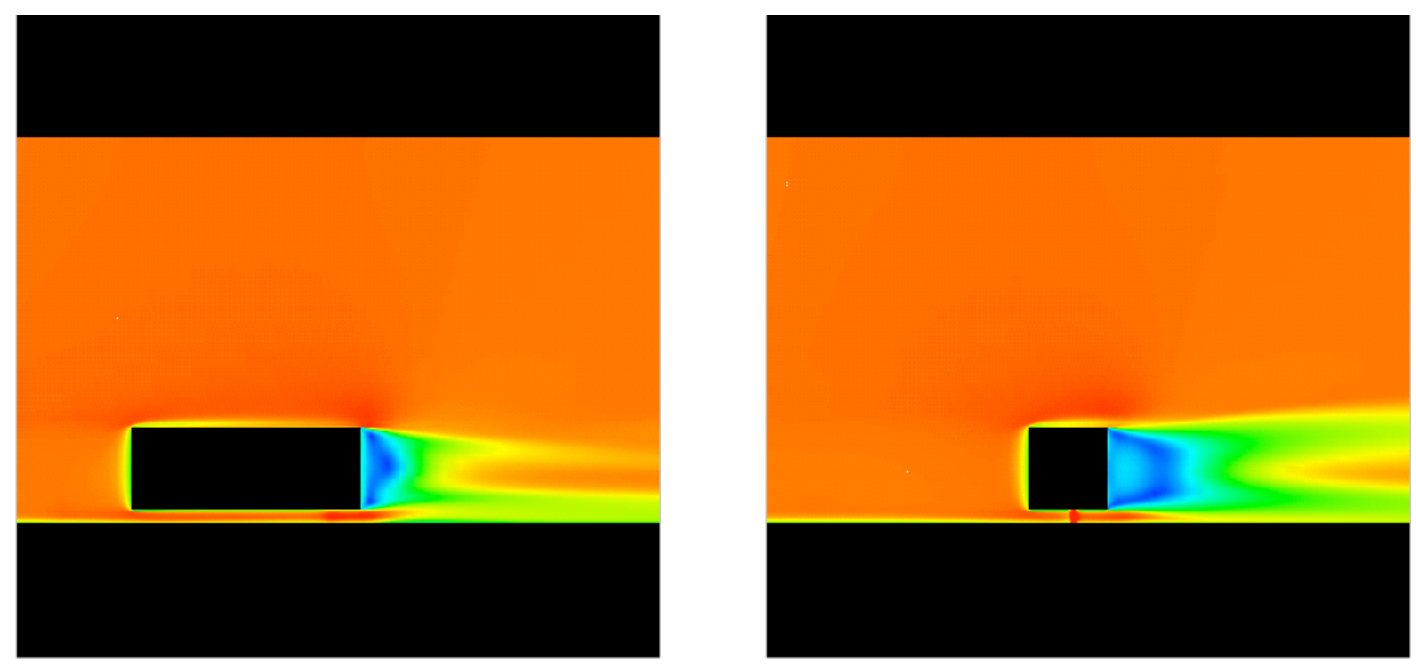

Figure 13: Mach contour, $x y$ slice, $z=0.07 \mathrm{~m}$ (left), $\mathrm{z}=0.215 \mathrm{~m}$ (right), $10^{\circ}$ yaw, medium grid. 


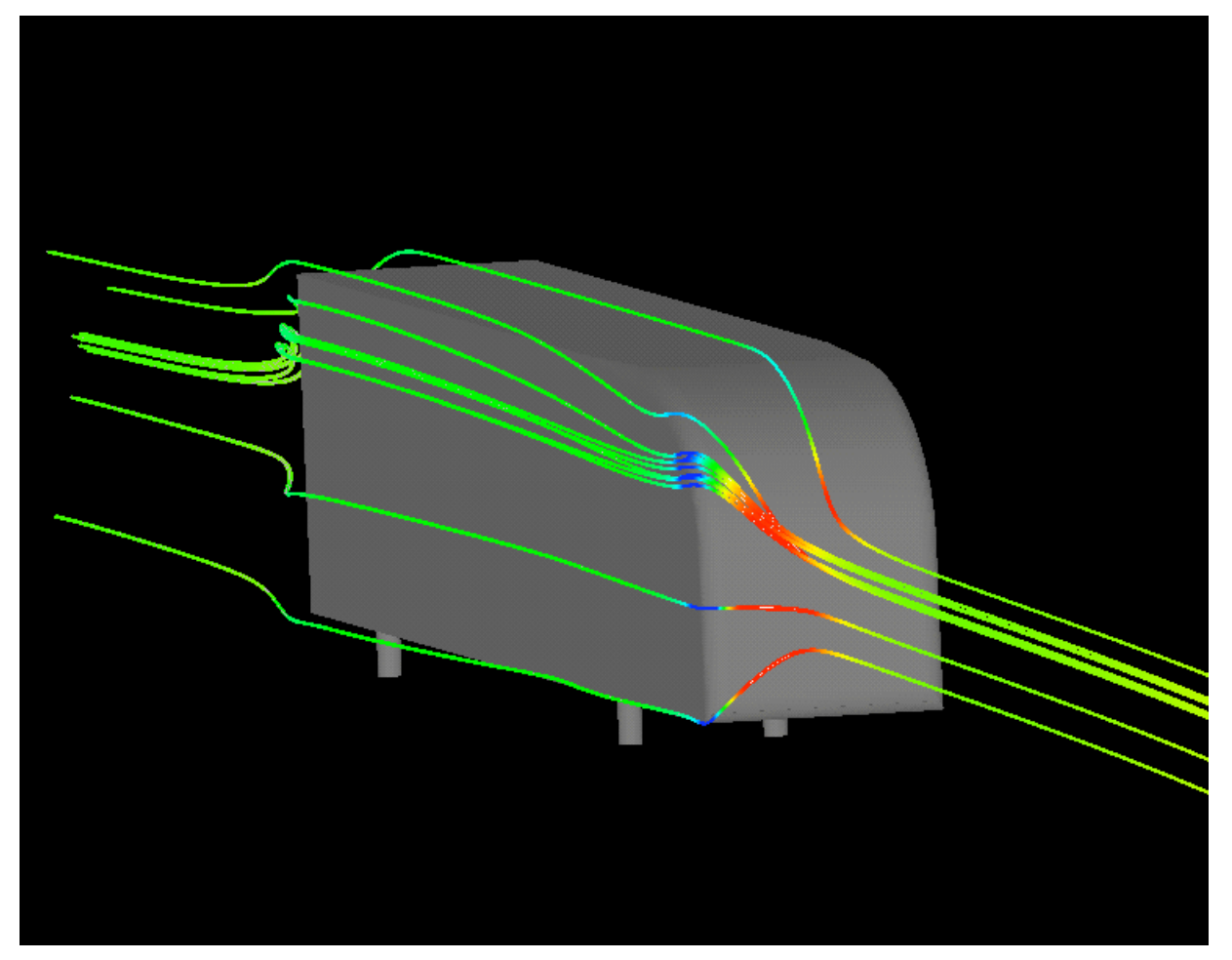

Figure 14: Particle traces colored by Mach number, $0^{\circ}$ yaw, medium grid. 

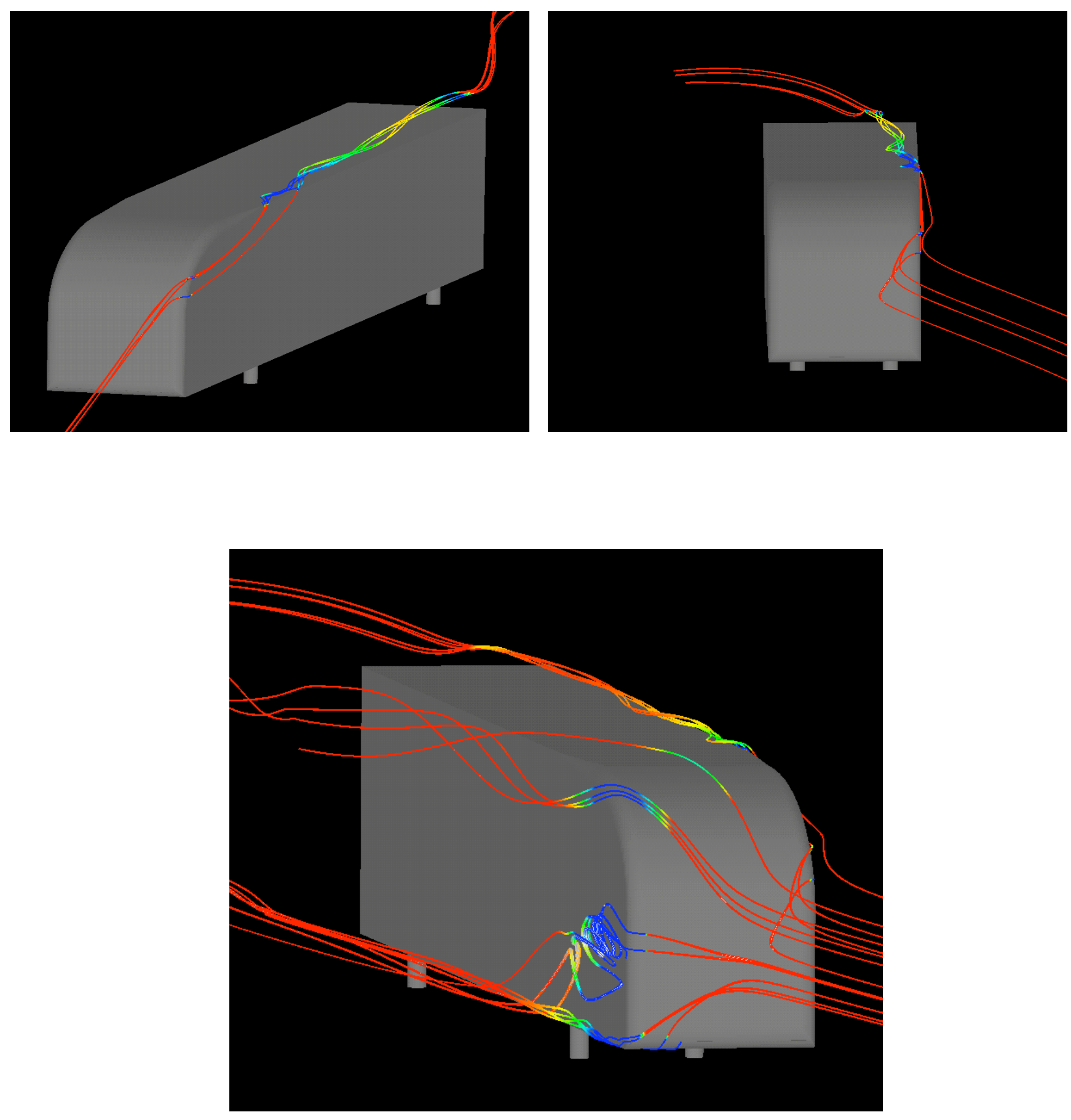

Figure 15: Particle traces colored by Mach number, $10^{\circ}$ yaw, and medium grid. 

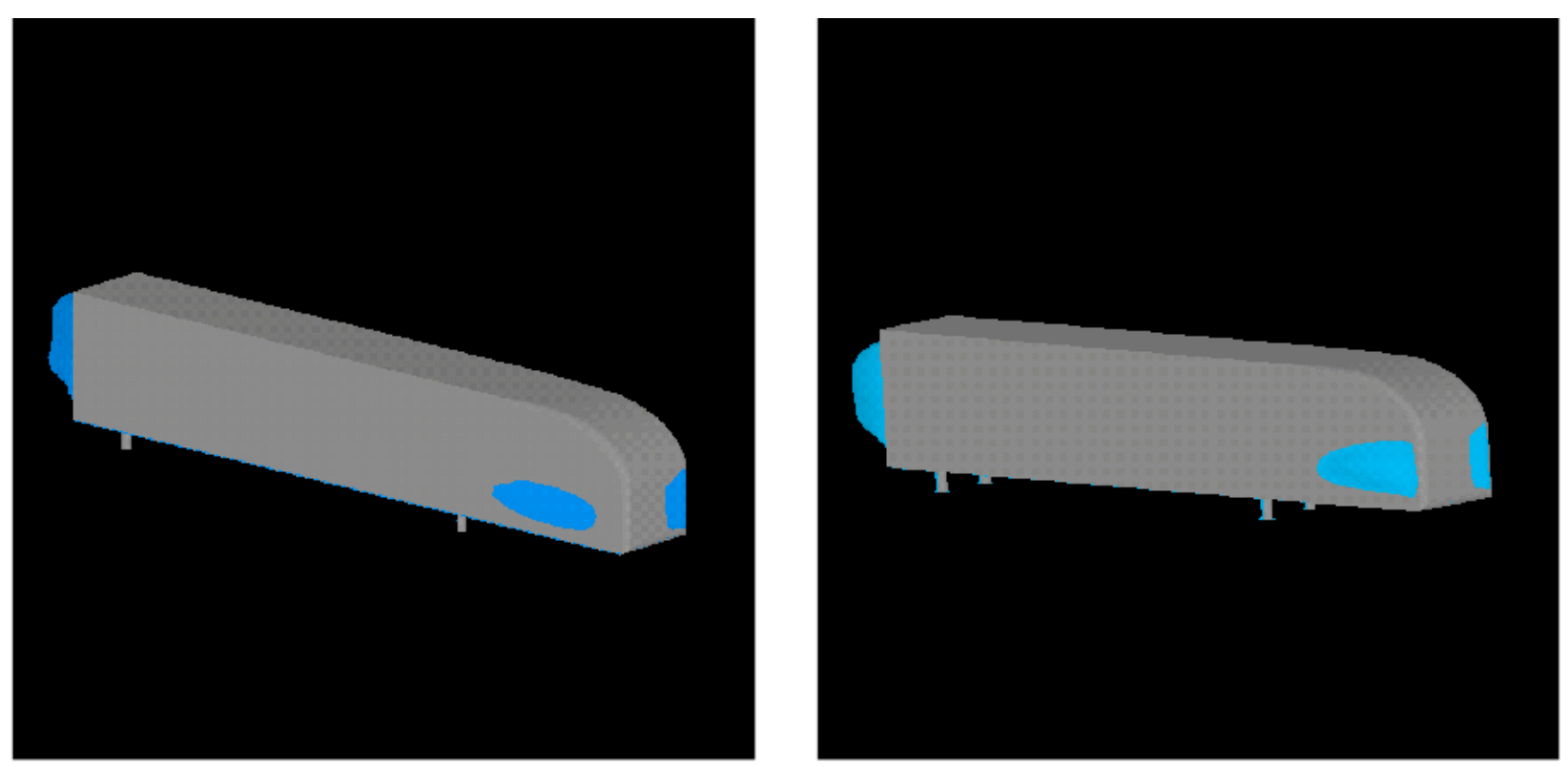

Figure 16: Iso-Surface for $u=-0.001$, coarse grid (left), medium grid (right), $10^{\circ}$ yaw. 


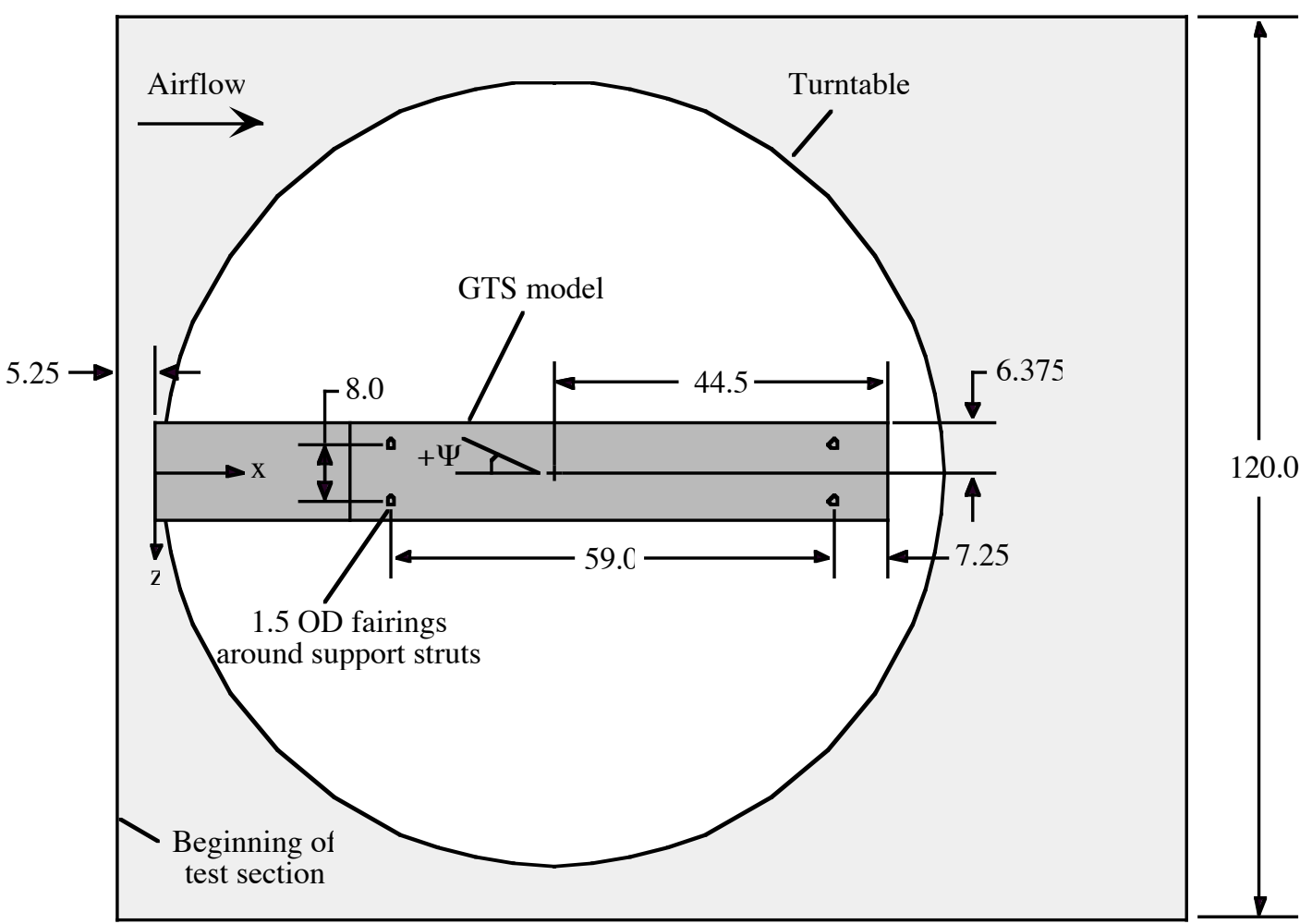

Figure 17: NASA Ames Experiment: GTS model installation top view (dimensions in inches). 


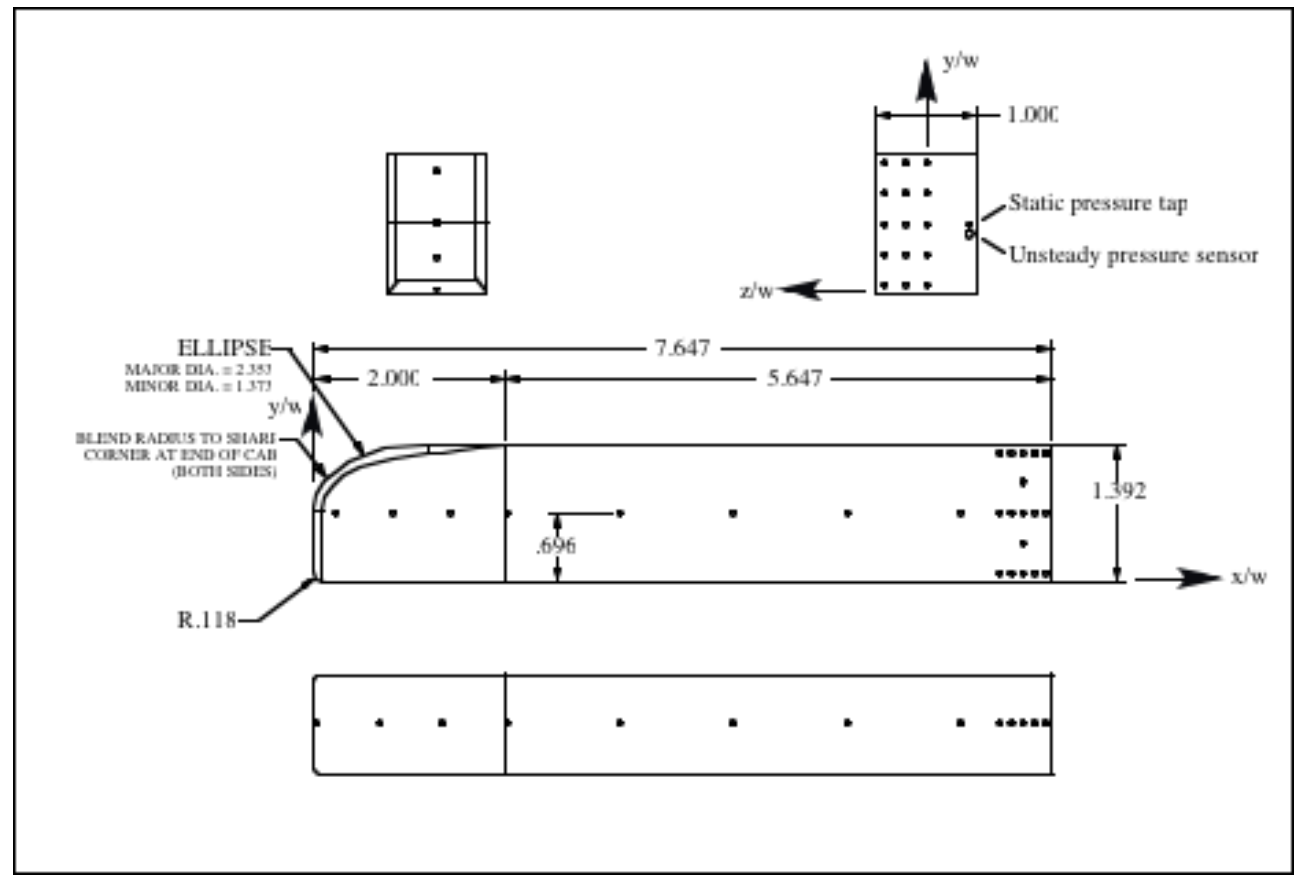

Figure 18: GTS geometry and pressure tap locations. All measurements nondimensionalized by trailer width, $w=12.75$ in $(32.38 \mathrm{~cm})$. 


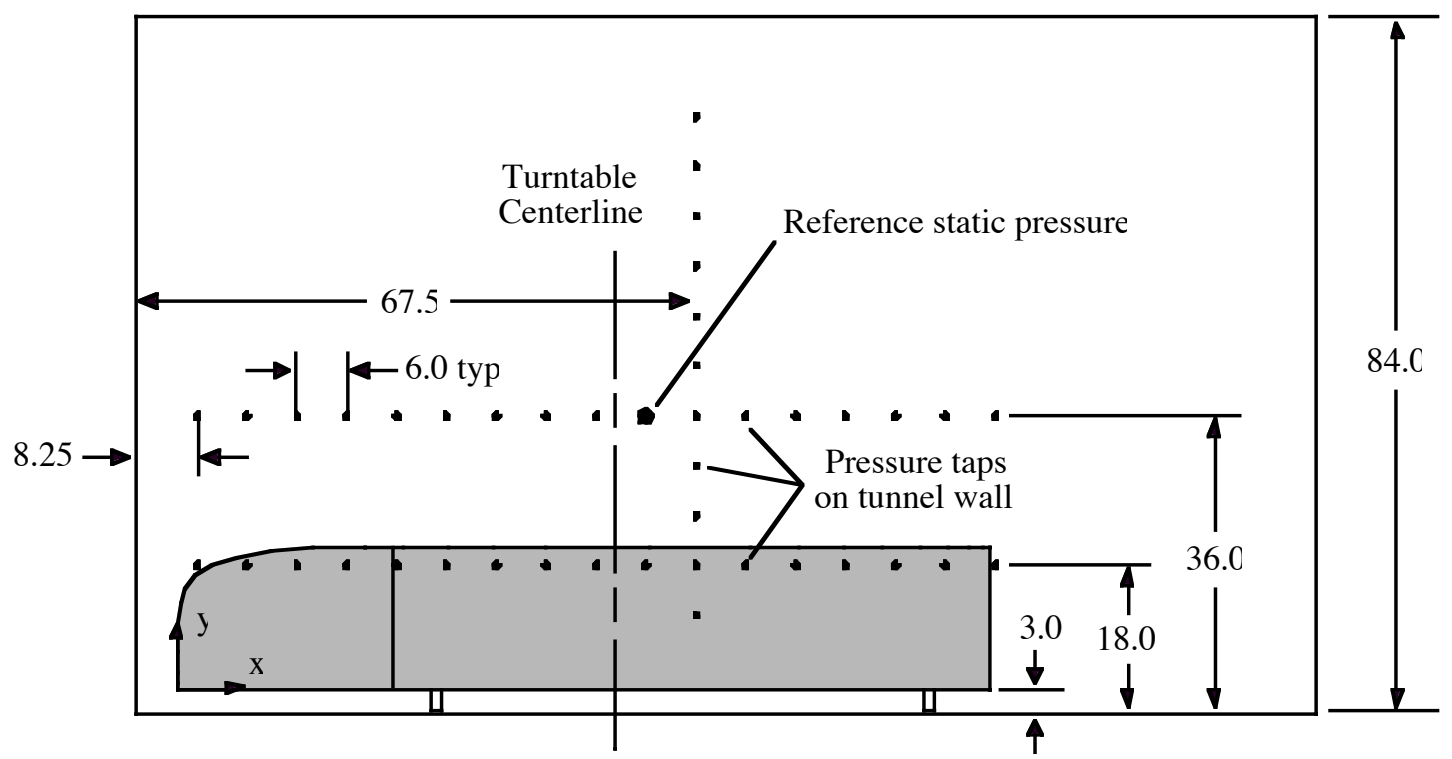

Figure 19: GTS model installation side view (dimensions in inches).

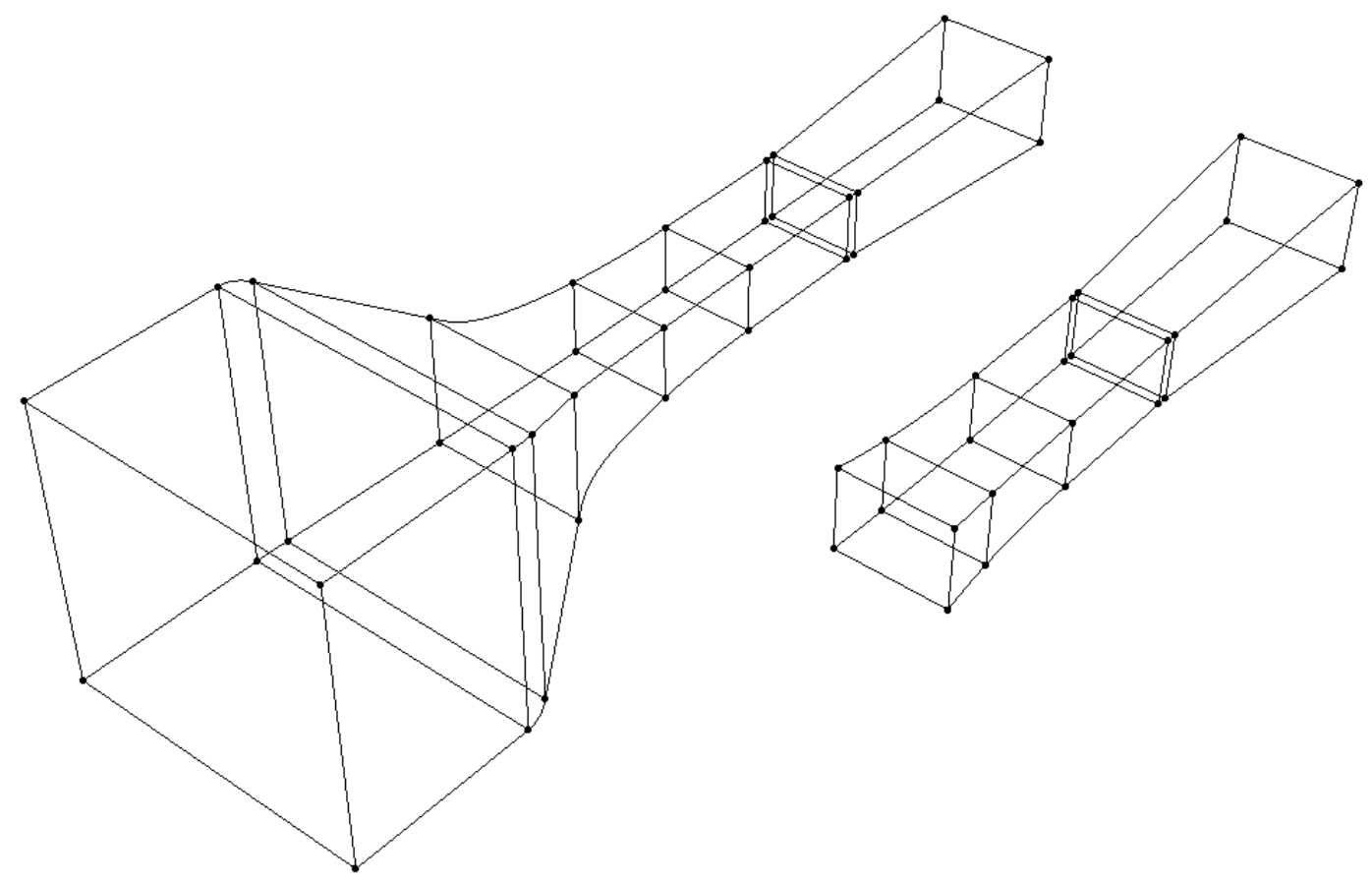

Figure 20: Schematic of a portion of the NASA $7 \times 10$ wind tunnel. 


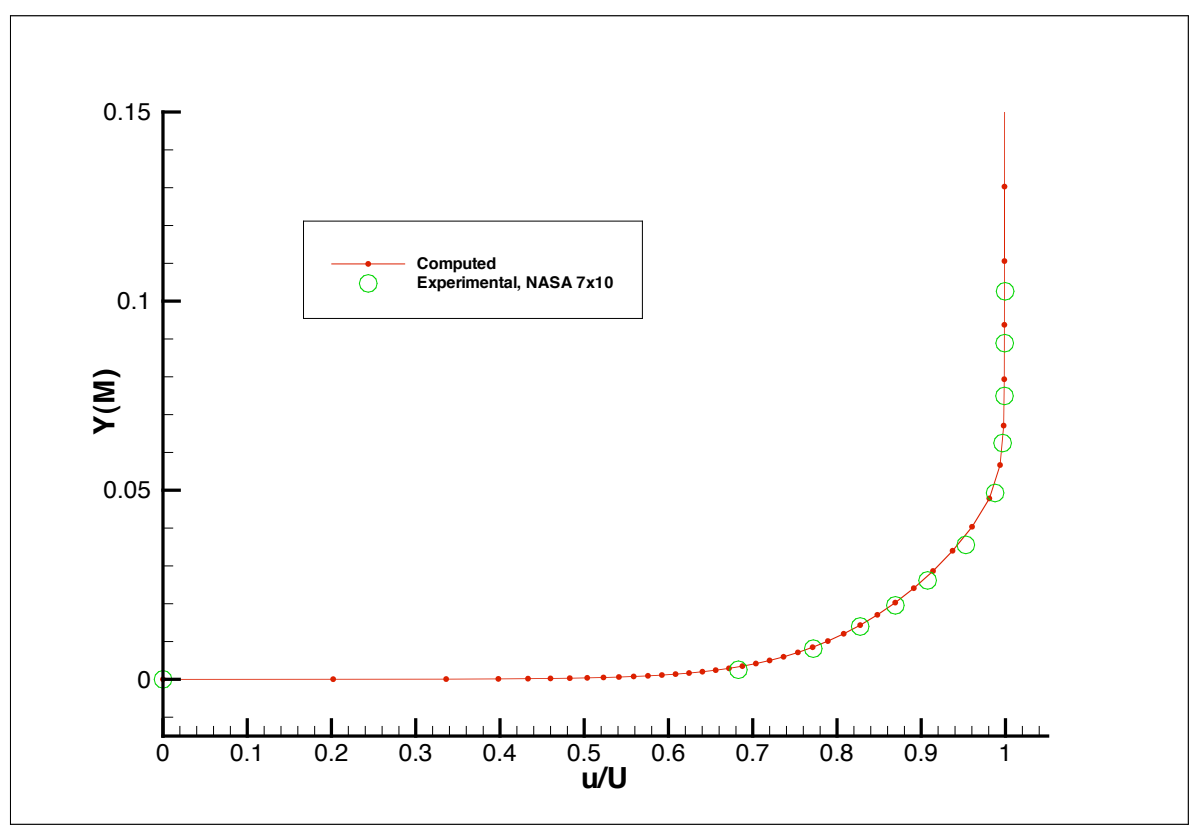

Figure 21: Boundary layer profile, NASA 7x10 test section centerline.

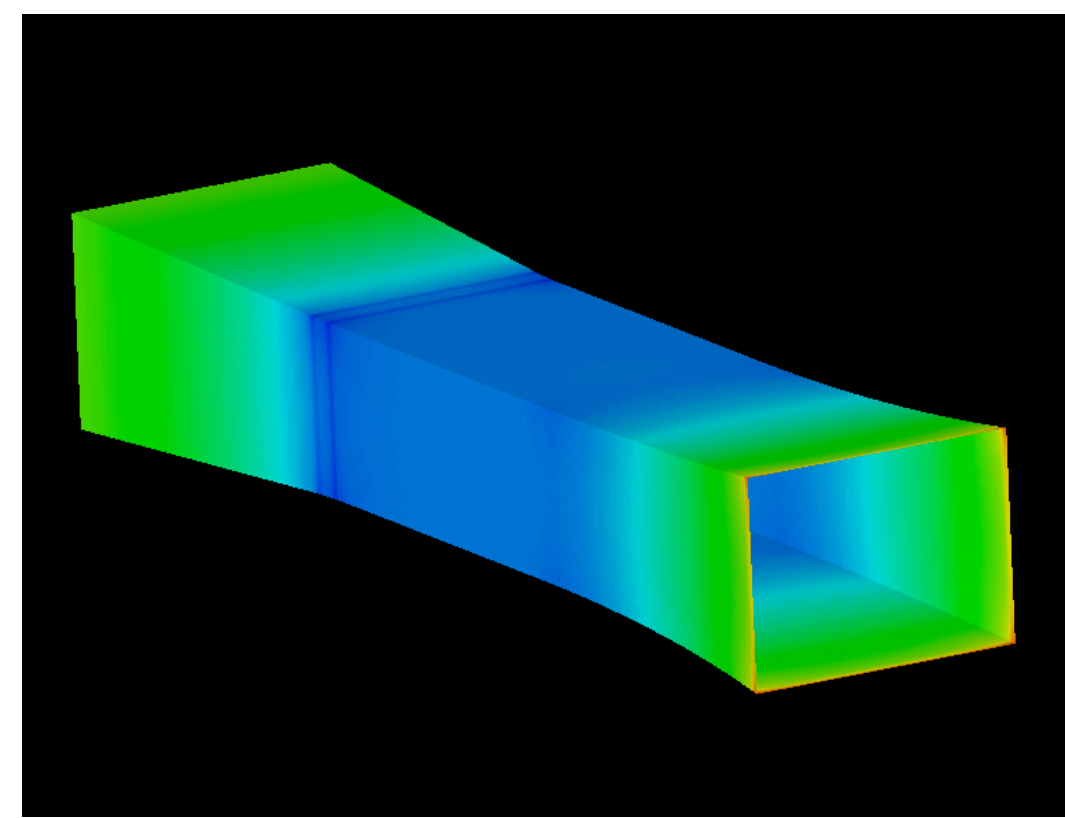

Figure 22: NASA 7x10 wind tunnel, pressure contours. 


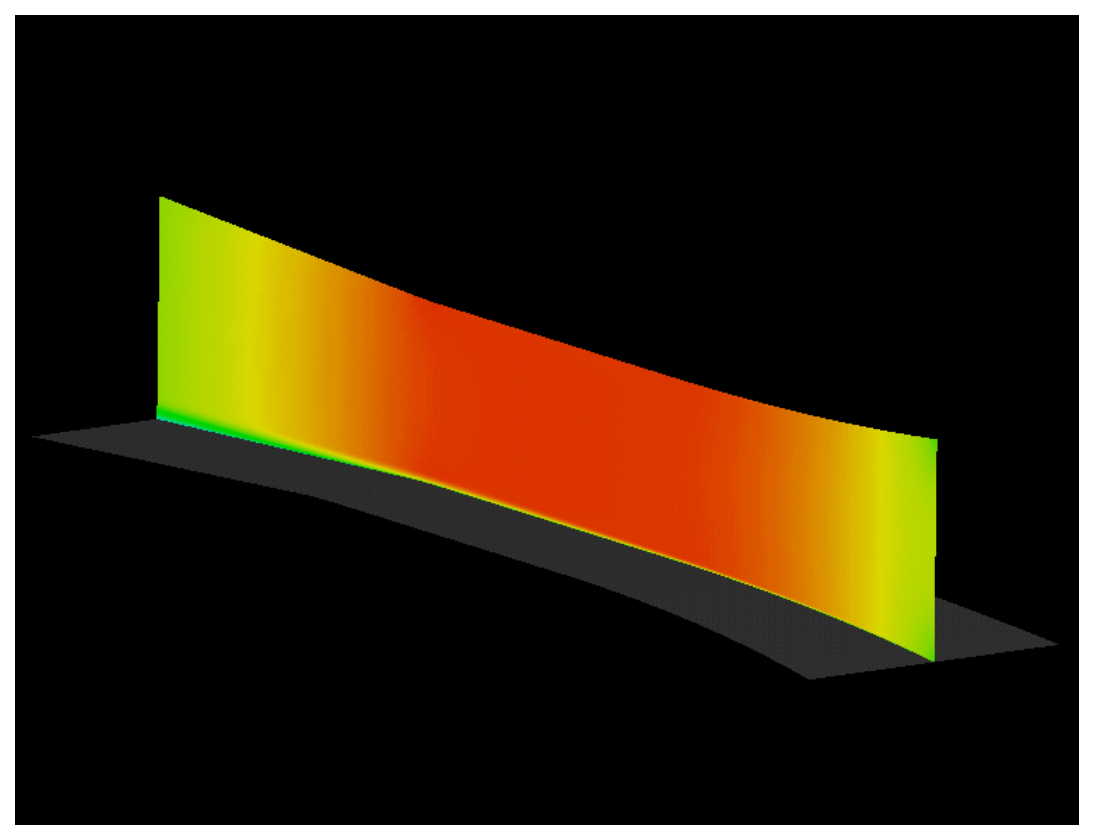

Figure 23: NASA 7x10 wind tunnel, center plane, Mach contours.

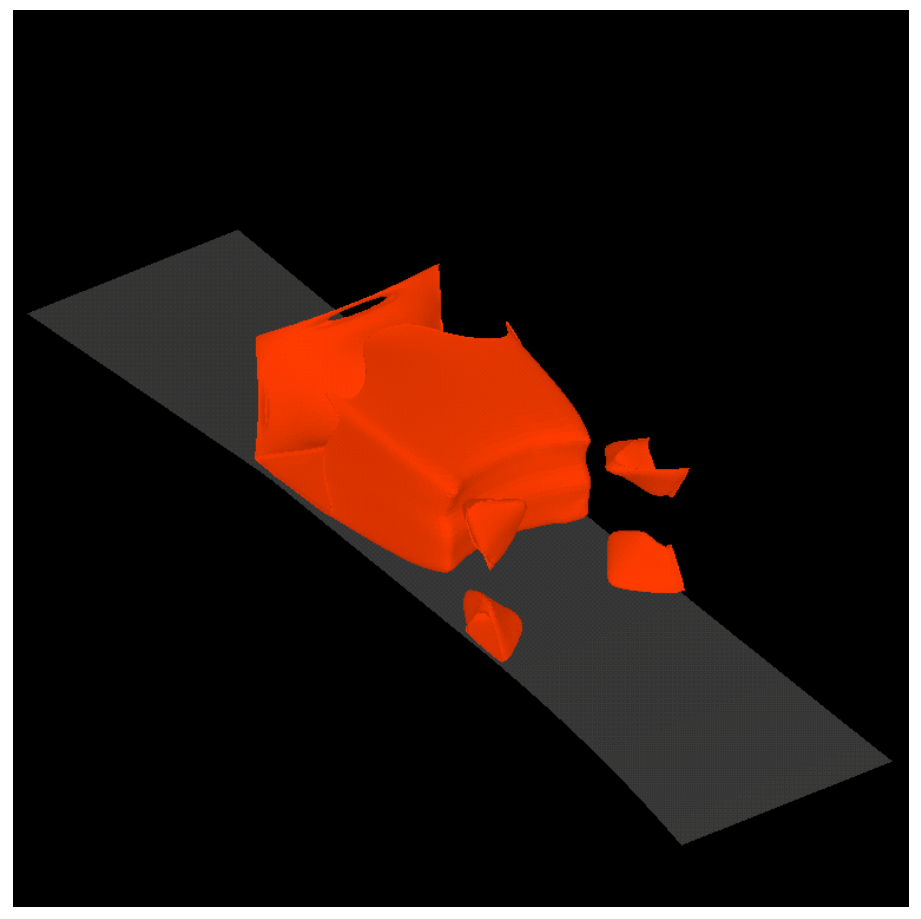

Figure 24: NASA 7×10 wind tunnel, Iso-Surface plot, u-component of velocity, $\mathrm{u}=89.92 \mathrm{~m} / \mathrm{s}$. 


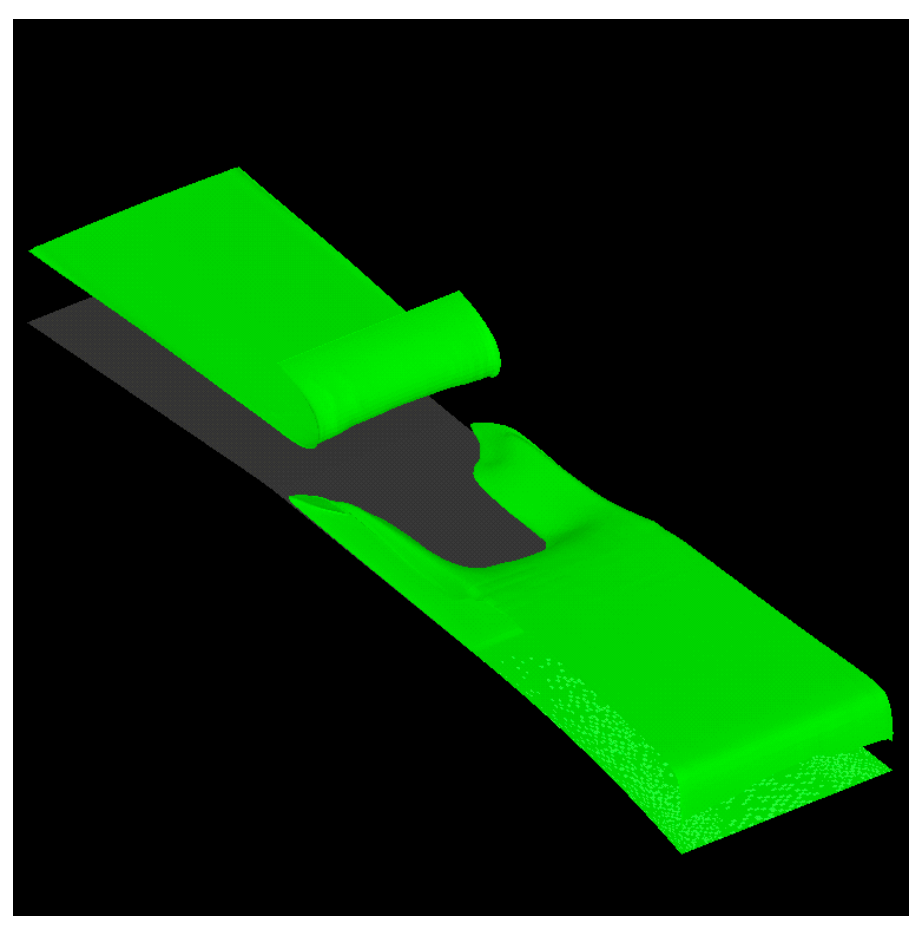

Figure 25: NASA 7x10 wind tunnel, Iso-Surface plot, v-component of velocity, $\mathrm{v}=0.1 \mathrm{~m} / \mathrm{s}$.

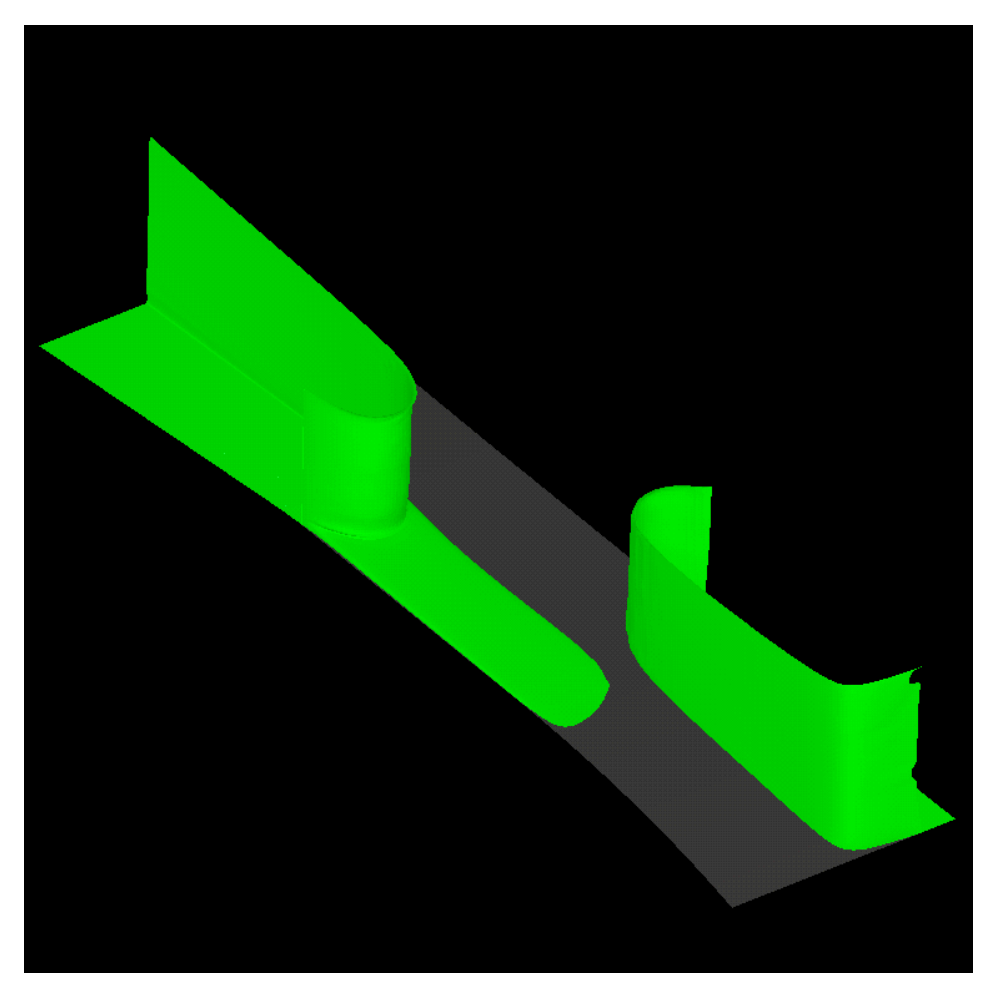

Figure 26: NASA 7x10 wind tunnel, Iso-Surface plot, w-component of velocity, $\mathrm{w}=-0.01 \mathrm{~m} / \mathrm{s}$. 


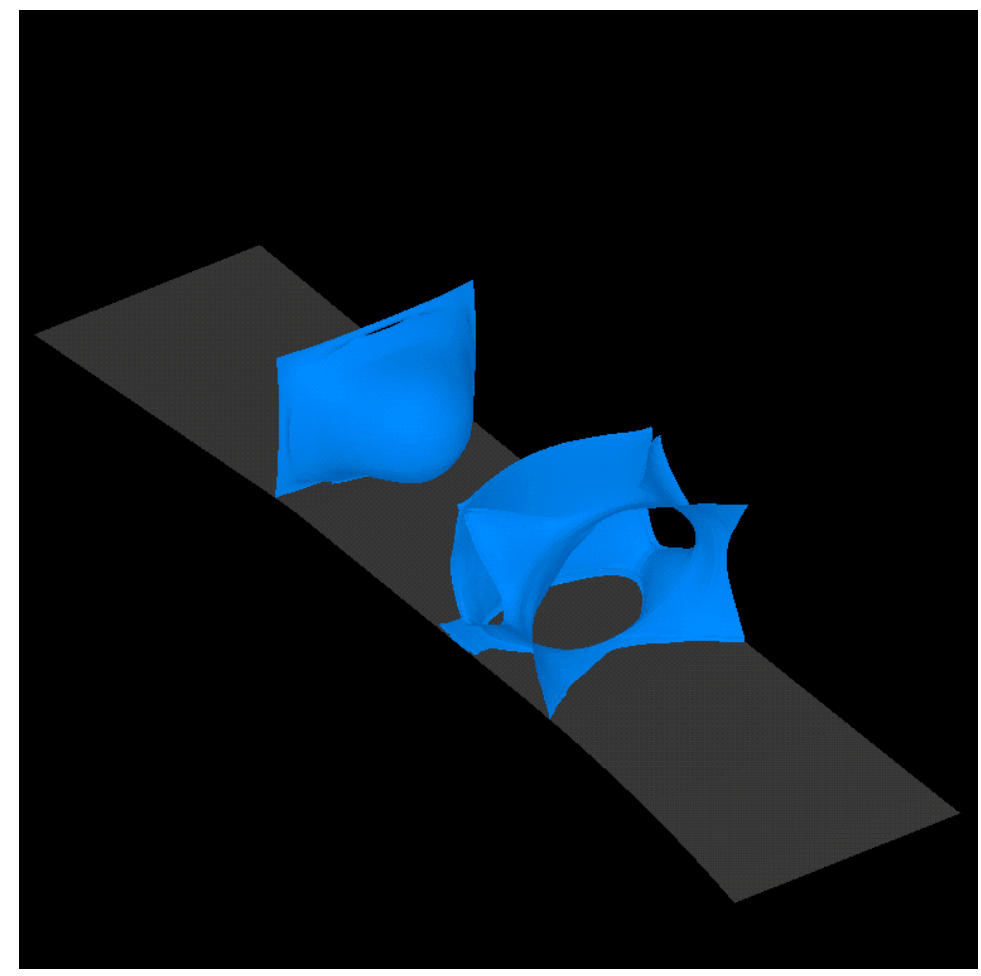

Figure 27: NASA 7x10 wind tunnel, Iso-Surface plot, pressure, $p=97613 \mathrm{~Pa}$

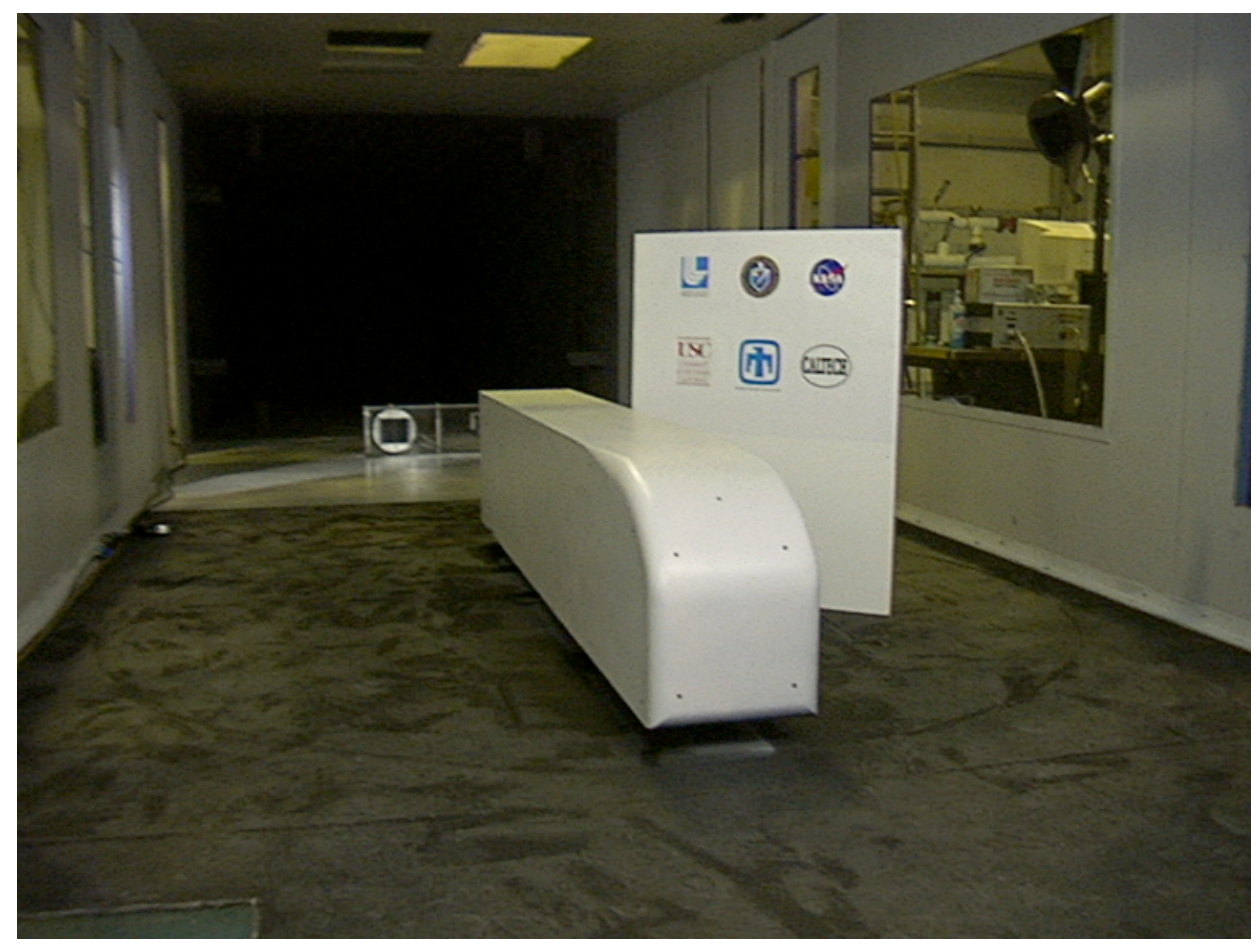

Figure 28: GTS model in NASA Ames 7x10 tunnel 


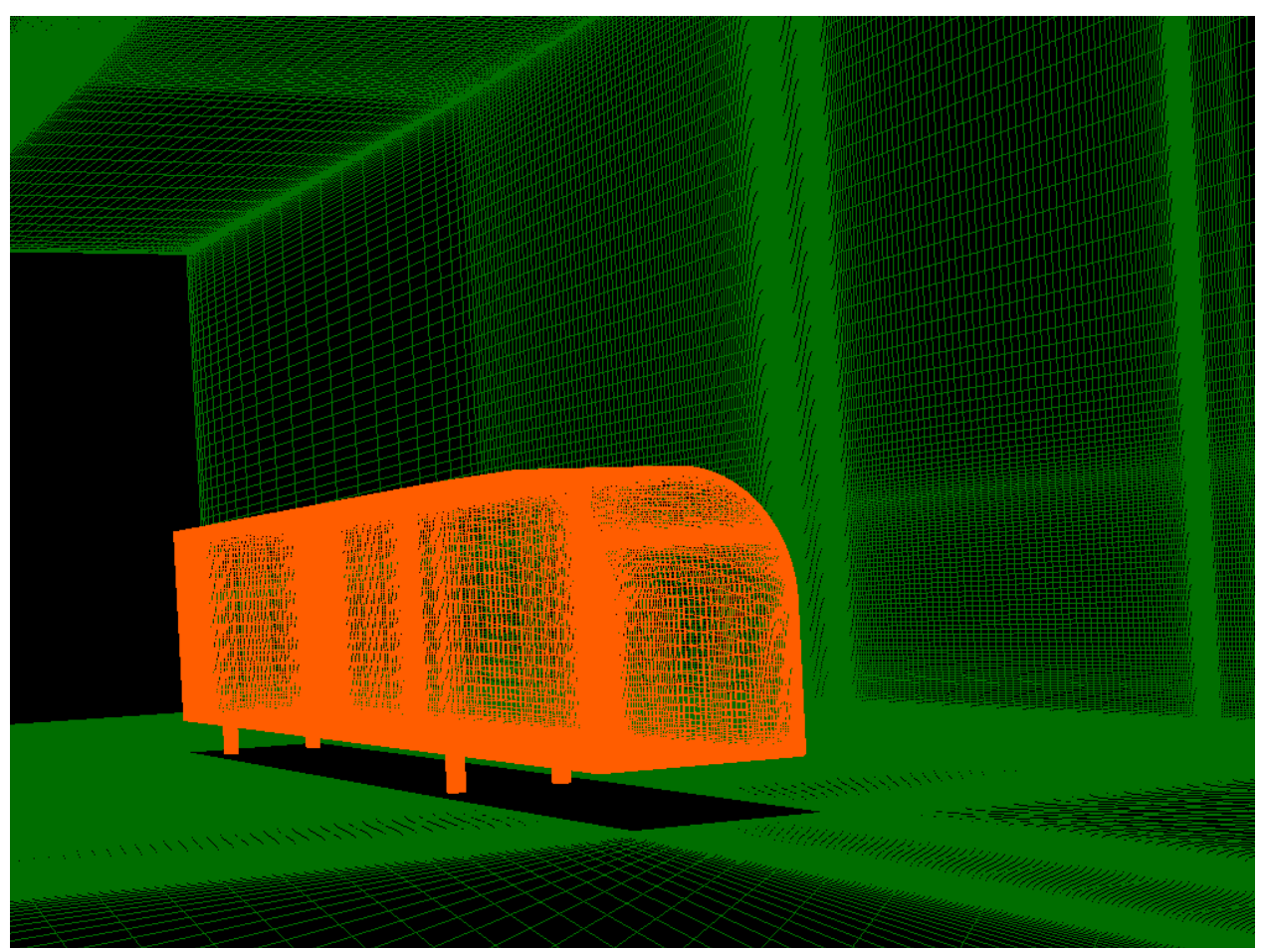

Figure 29: Medium mesh of the GTS model in NASA 7×10 tunnel
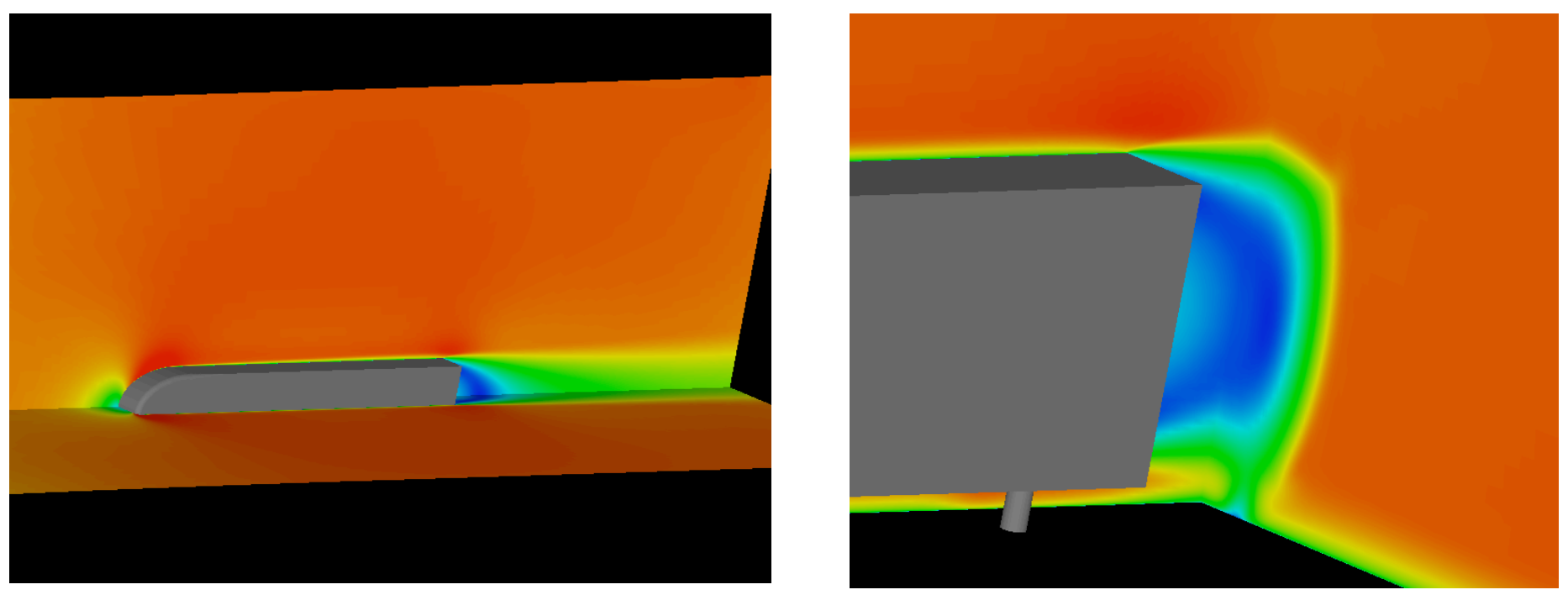

Figure 30: Mach Contours on Cutting Planes for Spalart-Allmaras Solution (Medium Mesh) 


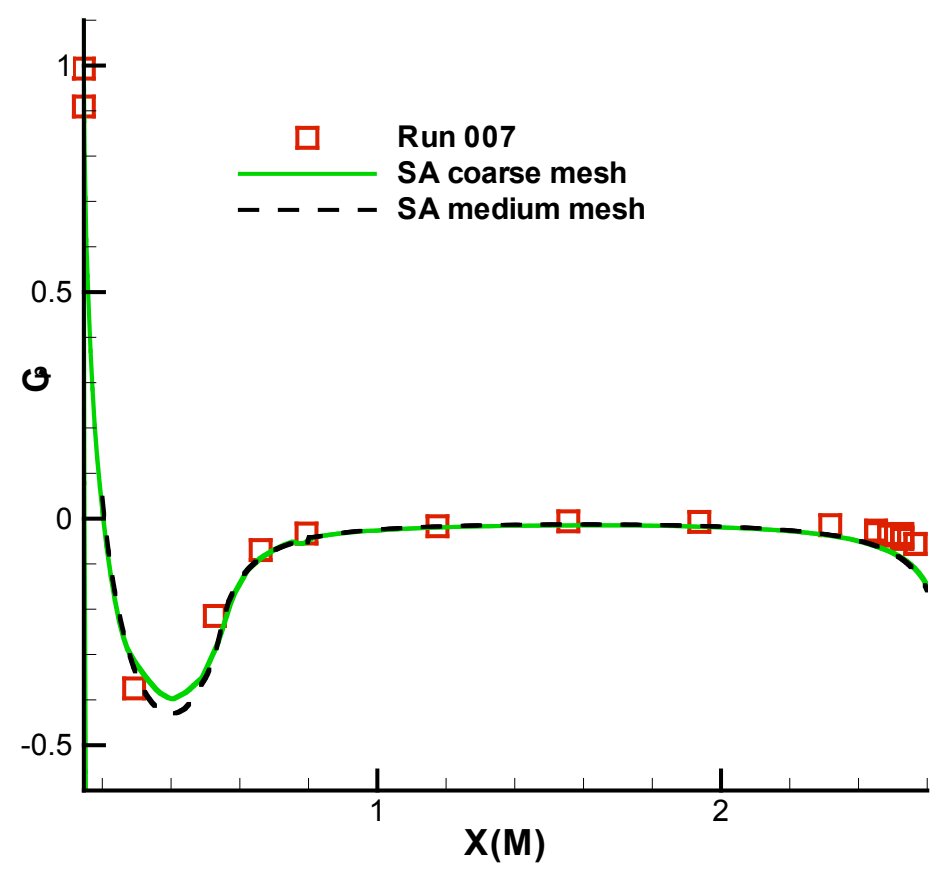

Figures 31: Centerline Front, Top of Truck Pressure Coefficient

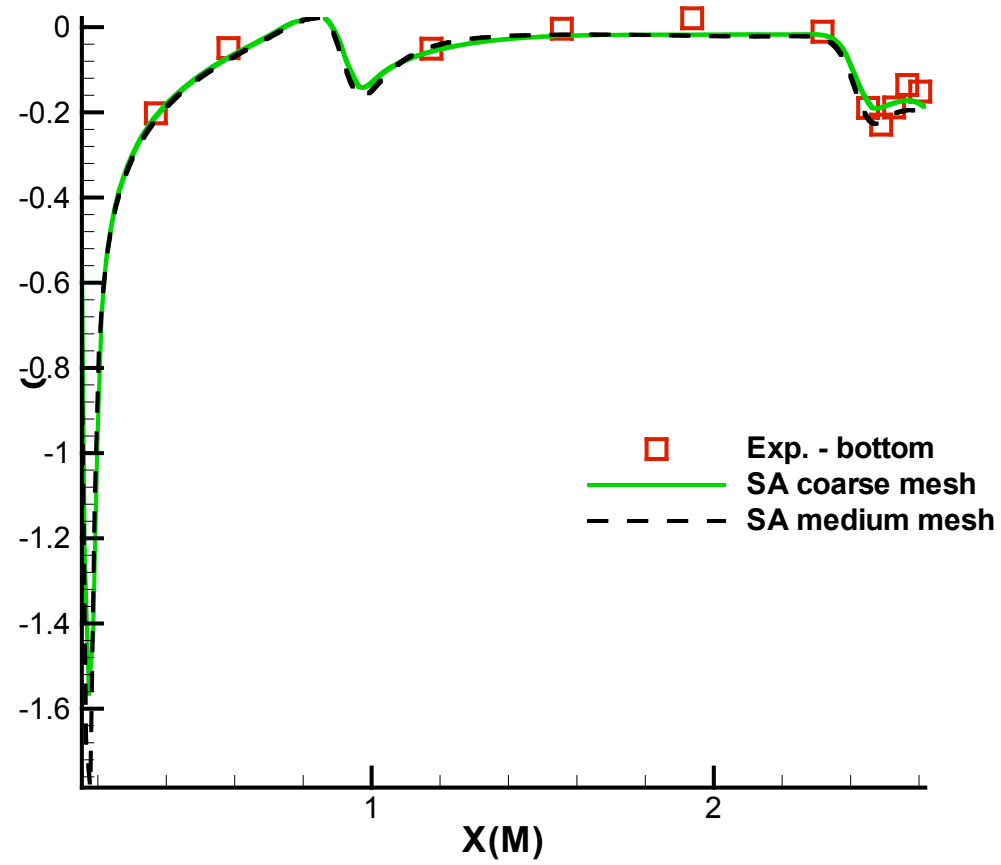

Figures 32: Centerline Front and Bottom of Truck Pressure Coefficient 


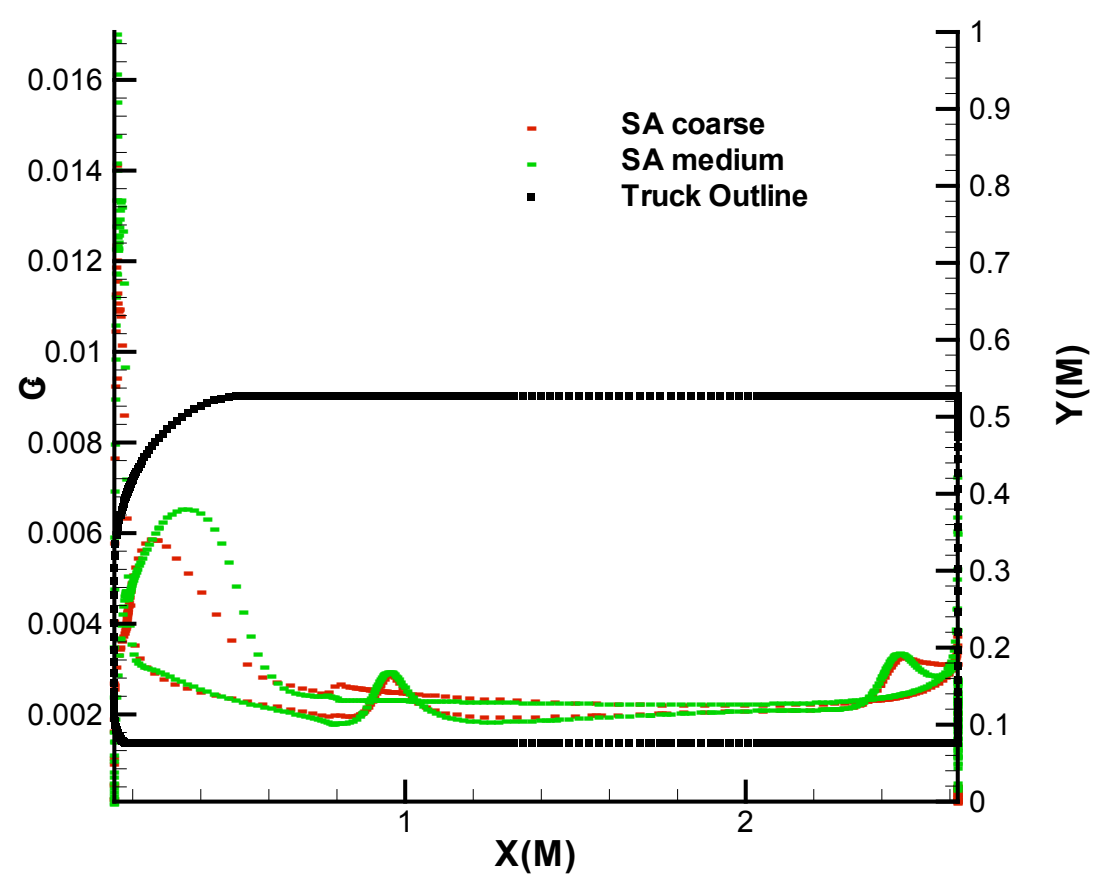

Figure 33: Skin Friction Coefficient on Centerline and Around the Truck

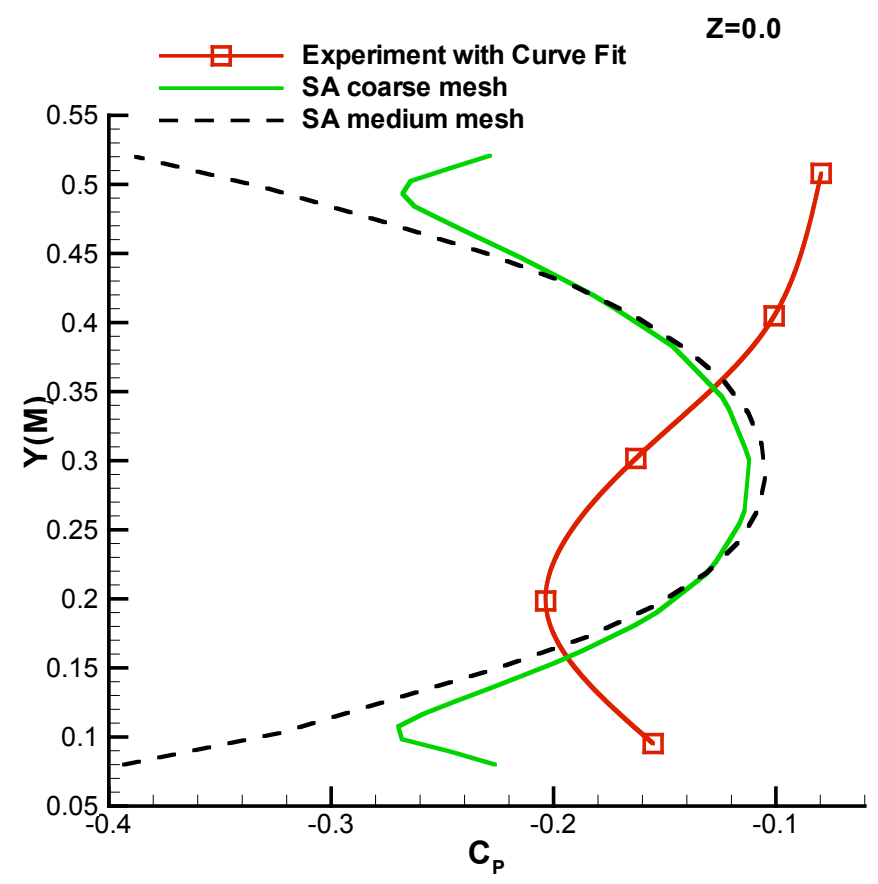

Figures 34: Pressure Coefficients on the Base at $Z=0.0 \mathrm{~m}$ 


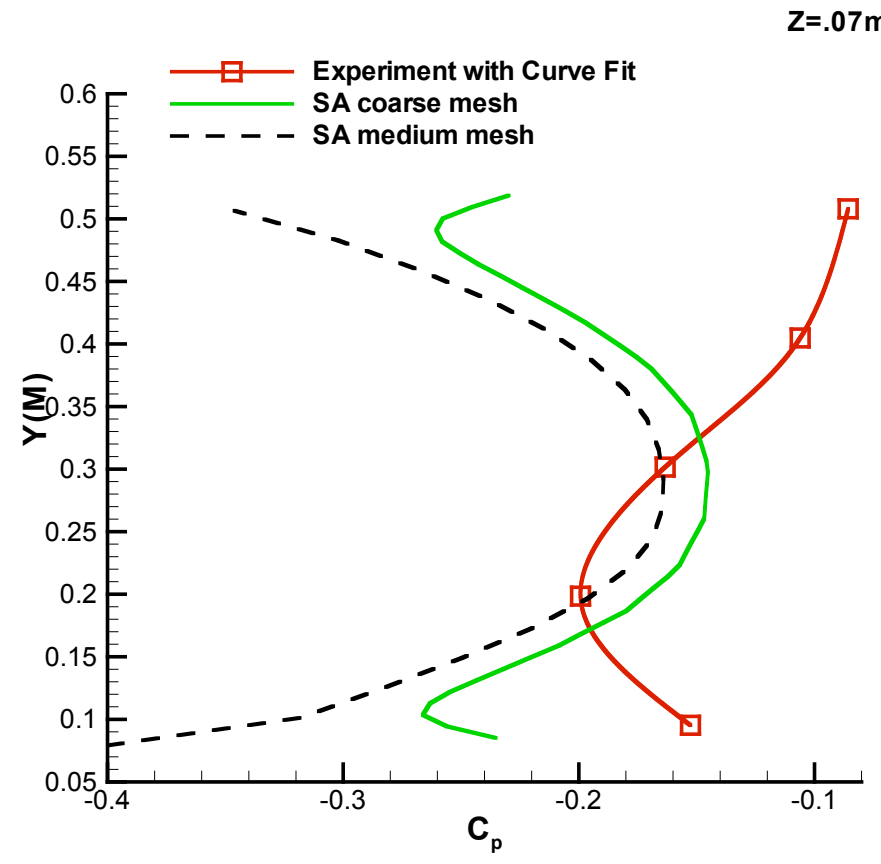

Figures 35: Pressure Coefficients on the Base at $Z=0.07 \mathrm{~m}$

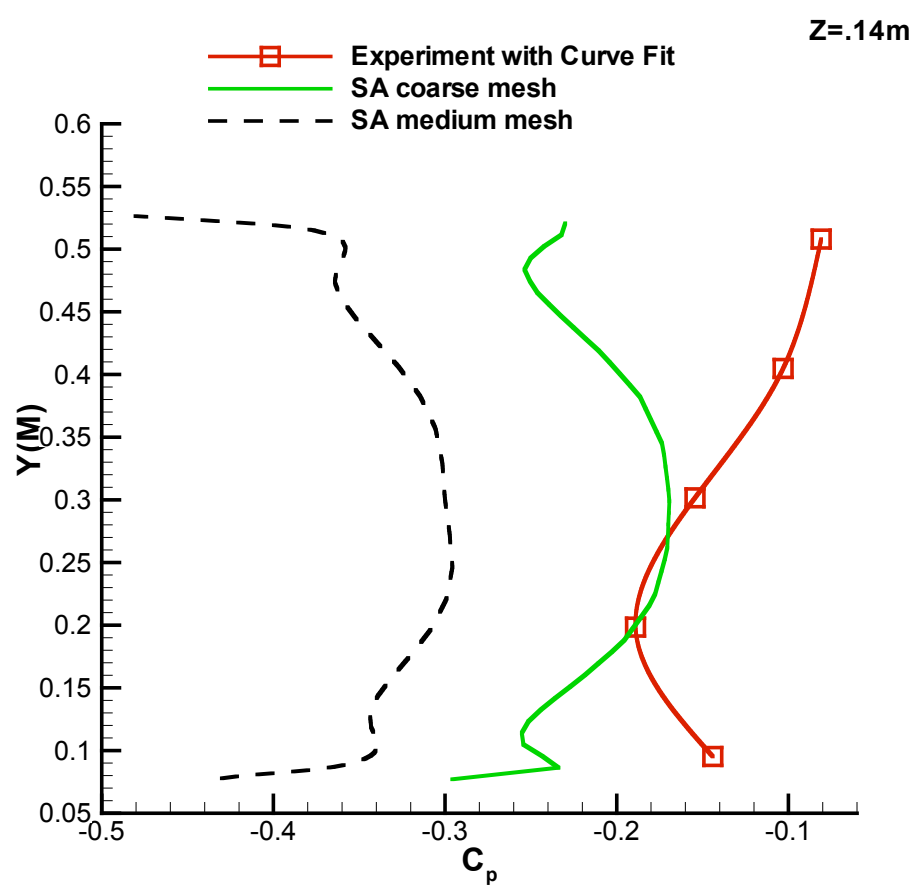

Figures 36: Pressure Coefficients on the Base at $Z=0.14 \mathrm{~m}$ 

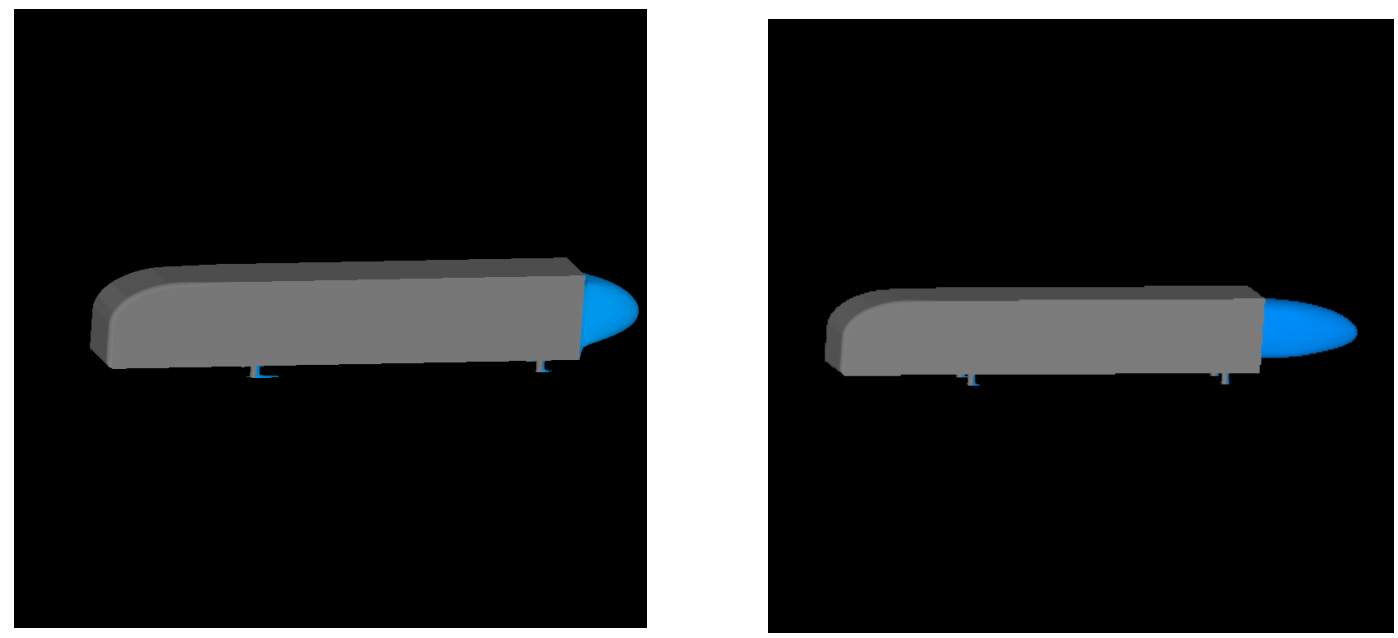

Figures 37 and 38: Contours of Negative U-Component of Velocity for SpalartAllmaras (left) and k-epsilon (right) Solutions on Medium Mesh
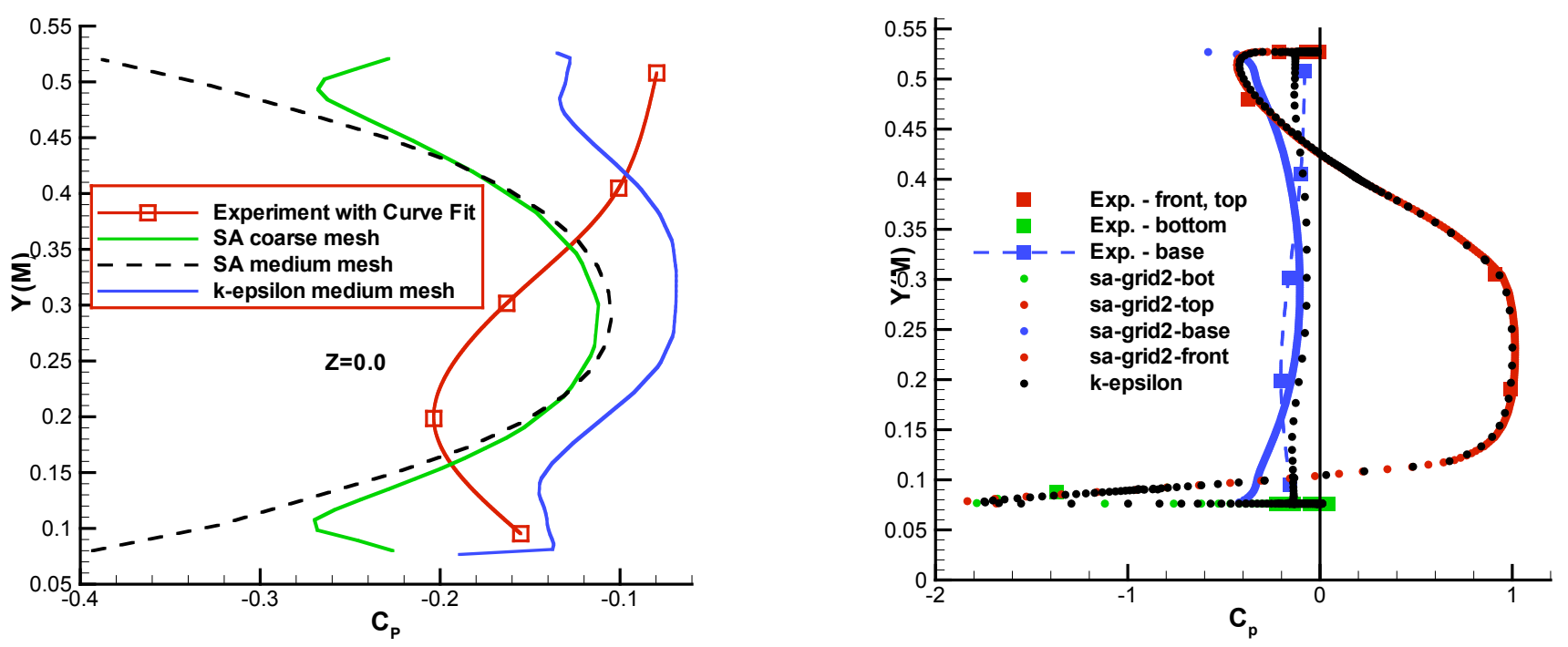

Figures 39 and 40: Pressure Coefficient Comparisons with Experiment on the Base (left) at $Z=0.0$ and Around the Centerline of the Truck (right) 


\section{References}

1. Highway Statistics 1992, p 207, US Government Printing Office, SSOP, Washington DC 20402-9328

2. Gutierrez, W. T., Hassan, B., Croll, R. H., Rutledge, W. H., "Aerodynamics Overview of the Ground Transportation Systems (GTS) Project for Heavy Vehicle Drag Reduction," SAE Paper No. 960906, Feb. 1996.

3. Croll, R. H., Gutierrez, W. T., Hassan, B., Suazo, J. E., and Riggins, A. J., "Experimental Investigation of the Ground Transportation Systems (GTS) Project for Heavy Vehicle Drag Reduction," SAE Paper No. 960907, Feb. 1996.

4. Steen, G., "Subsonic Wind Tunnel Test of the Sandia National Laboratories Ground Transportation Vehicle," TEES Report No. TR-9514, July 1995.

5. Storms, B., et. al., "An Experimental Study of the Ground Transportation System (GTS) Model in the NASA Ames 7- by 10-Ft Wind Tunnel," NASA/TM-2001-209621, Feb. 2001.

6. Wong, C. C., Soetrisno, M., Blottner, F. G., Imlay, S. T., and Payne, J. L., "PINCA: A Scalable Parallel Program for Compressible Gas Dynamics with Nonequilibrium Chemistry," SAND 94-2436, Sandia National Laboratories, Albuquerque, NM, 1995.

7. Wong, C. C., Blottner, F. G., Payne, J. L., and Soetrisno, M., "Implementation of a Parallel Algorithm for Thermo-Chemical Nonequilibrium Flow Solutions," AIAA Paper No. 95-0152, Jan. 1995.

8. INCA User's Manual, Version 2.0, Amtec Engineering, Inc., Bellevue, WA, 1995. 


Distribution:
$\begin{array}{llll}1 & \text { MS } 0841 & 9100 & \text { T. C. Bickel } \\ 1 & \text { MS } 0824 & 9110 & \text { W. L. Hermina } \\ 1 & \text { MS } 0834 & 9112 & \text { M. R. Prairie } \\ 1 & \text { MS } 0834 & 9112 & \text { V. A. Amatucci } \\ 1 & \text { MS } 0834 & 9112 & \text { S. J. Beresh } \\ 1 & \text { MS } 0834 & 9112 & \text { C. J. Bourdon } \\ 1 & \text { MS } 0835 & 9113 & \text { S. N. Kempka } \\ 1 & \text { MS } 0834 & 9114 & \text { J. E. Johannes } \\ 5 & \text { MS } 0825 & 9115 & \text { B. Hassan } \\ 1 & \text { MS } 0825 & 9115 & \text { M. F. Barone } \\ 1 & \text { MS } 0825 & 9115 & \text { F. G. Blottner } \\ 1 & \text { MS } 0825 & 9115 & \text { R. B. Bond } \\ 1 & \text { MS } 0825 & 9115 & \text { L. J. DeChant } \\ 1 & \text { MS } 0825 & 9115 & \text { D. W. Kuntz } \\ 10 & \text { MS } 0825 & 9115 & \text { M. A. McWherter-Payne } \\ 1 & \text { MS } 0825 & 9115 & \text { J. L. Payne } \\ 1 & \text { MS } 0836 & 9116 & \text { E. S. Hertel } \\ 1 & \text { MS } 0836 & 9117 & \text { R. O. Griffith } \\ 1 & \text { MS } 0847 & 9120 & \text { H. S. Morgan } \\ 1 & \text { MS } 0824 & 9130 & \text { J. L. Moya } \\ 1 & \text { MS } 0835 & 9140 & \text { J. M. McGlaun } \\ 1 & \text { MS } 0753 & 6245 & \text { J. B. Kelley } \\ 1 & \text { MS } 1174 & 15414 & \text { W. H. Rutledge } \\ 1 & \text { MS } 9018 & 8945-1 \text { Central Technical } \\ & & & \text { Files } \\ 2 & \text { MS } 0899 & 9616 & \text { Technical Library } \\ & & & \text { Files }\end{array}$

\section{External Distribution:}

Chris Roy

Dept. of Aerospace Engineering

211 Aerospace Engineering Bldg.

Auburn University, AL 36849-5338

Rick R. Balthaser

Science and Technology Programs, Sandia Site Office

U.S. DOE/NNSA

P.O. Box 5400

Albuquerque, NM 87185

T. A. Dunn

Lawrence Livermore National Laboratory

7000 East Ave, L-228

PO Box 808, L-228

Livermore, CA 94550 


\section{External Distribution: (Con't)}

B. Storms

NASA Ames Research Center

MS247-2

Moffett Field, CA 94035-1000

R. C. McCallen

Lawrence Livermore National Laboratory

7000 East Ave., L-098

PO Box 808, L-098

Livermore, CA 94550

B. Englar

Georgia Tech Research Inst.

ATASL, CCRF

Atlanta, GA 30332-0844

M. Hammache

University of Southern California

AME Dept. RRB214-USC

Los Angeles, CA 90089-1191

A. Leonard

California Institute of Technology

1200 East California Blvd. M/C 301-46

Pasadena, CA 91125

J. Ross

NASA Ames Research Center

MS 260-1

Moffett Field, CA 94035

D. Satran

NASA Ames Research Center

MS 260-1

Moffett Field, CA 94035

F. Browand

University of Southern CA

Dept. of Aero. Engr., RAPP 203

Los Angeles, CA 90089-1191 


\section{External Distribution: (Con't)}

K. Salari

Lawrence Livermore National Laboratory

7000 East Ave, L-228

PO Box 808, L-228

Livermore, CA 94550

T. Hsu

University of Southern California

Aerospace and Mechanical Eng.

OHE 430

Los Angeles, CA 90089

J. Ortega

Lawrence Livermore National Laboratory

7000 East Ave L-228

PO Box 808, L-228

Livermore, CA 94550

D. R. Arcas

University of Southern California

853 West 36th Place

Los Angeles, CA 90089-1191

M. Rubel

Caltech

MC 205-45

Pasadena, CA 91125

P. Chatelain

Caltech, Aeronautical Laboratory

1200 East California Blvd.

Pasadena, CA 91125

T. Sofu

Argonne National Laboratory

9700 S. Cass Ave RAE-208

Argonne, IL 60439

D. T. Yen-Nakafuji

Lawrence Livermore National Laboratory

7000 East Ave, L-644

PO Box 808, L-644

Livermore, CA 94550 
External Distribution: (Con't)

D. Pointer

Argonne National Laboratory

9700 S. Cass Ave, RAE-208

Argonne, IL 60439

J. Routbort

Argonne National Laboratory

9700 South Case Avenue

Argonne, IL 60439

D. Weber

Argonne National Laboratory

9700 S. Cass Ave RE 208 C218

Argonne, IL 60439

S. Walker

NASA Ames Research Center

Mail Stop 260-1

Moffett Field, CA 94035-1000

J. T. Heineck

NASA Ames Research Center

M.S. 260-1

Moffett Field, CA 94035-1000

S. Diamond

DOE Heavy Vehicle System Technologies

1000 Independence Avenue, SW, EE-33

Washington, DC 20585

L. Dixon

Dept. of Aeronautics * MC 301-46

California Institute of Technology

Pasadena, CA. 91125-4600 